\title{
Directed generosity and network formation: network dimension matters
}

Citation for published version (APA):

d'Exelle, B., \& Riedl, A. M. (2010). Directed generosity and network formation: network dimension matters. METEOR, Maastricht University School of Business and Economics. METEOR Research Memorandum No. 065 https://doi.org/10.26481/umamet.2010065

Document status and date:

Published: 01/01/2010

DOI:

10.26481/umamet.2010065

Document Version:

Publisher's PDF, also known as Version of record

\section{Please check the document version of this publication:}

- A submitted manuscript is the version of the article upon submission and before peer-review. There can be important differences between the submitted version and the official published version of record.

People interested in the research are advised to contact the author for the final version of the publication, or visit the DOI to the publisher's website.

- The final author version and the galley proof are versions of the publication after peer review.

- The final published version features the final layout of the paper including the volume, issue and page numbers.

Link to publication

\footnotetext{
General rights rights.

- You may freely distribute the URL identifying the publication in the public portal. please follow below link for the End User Agreement:

www.umlib.nl/taverne-license

Take down policy

If you believe that this document breaches copyright please contact us at:

repository@maastrichtuniversity.nl

providing details and we will investigate your claim.
}

Copyright and moral rights for the publications made accessible in the public portal are retained by the authors and/or other copyright owners and it is a condition of accessing publications that users recognise and abide by the legal requirements associated with these

- Users may download and print one copy of any publication from the public portal for the purpose of private study or research.

- You may not further distribute the material or use it for any profit-making activity or commercial gain

If the publication is distributed under the terms of Article $25 \mathrm{fa}$ of the Dutch Copyright Act, indicated by the "Taverne" license above, 


\section{Maastricht University}

Ben D'Exelle, Arno Riedl

Directed Generosity and Network Formation: Network Dimension Matters

$\mathrm{RM} / 10 / 065$

\section{METEOR}

Maastricht University School of Business and Economics

Maastricht Research School of Economics

of Technology and Organization

\section{P.O. Box 616}

NL - 6200 MD Maastricht

The Netherlands 


\title{
Directed Generosity and Network Formation: Network Dimension Matters*
}

\author{
Ben D'Exelle Arno Riedl
}

December 4, 2010

\begin{abstract}
We explore network effects on generosity for different network dimensions. To this end we elicit multiple network dimensions (friendship, social support, economic exchange, etc.) in a rural village in the Southern hemisphere and measure generosity with a sequence of dictator games conducted in the field. We find that networks of different dimensions differ substantially in density, clustering, and centrality. When relating generosity to networks we observe that social distance only matters for friendship ties but that structural network variables are important in all network dimensions. Importantly, these effects are not invariant across different network dimensions. We also find that individual characteristics are unrelated with generosity per se but that they have strong explanatory power for network formation.
\end{abstract}

Keywords: Networks, generosity, network formation, experiments

JEL Classification: C72, C90, D64, L14, Z13

*Ben D'Exelle: University of East Anglia, School of International Development, NR4 7TJ, Norwich, United Kingdom, b.dexelle@uea.ac.uk; Arno Riedl: CESifo, IZA, and Maastricht University, Department of Economics (AE1), P.O. Box 616, 6200 MD Maastricht, the Netherlands, a.riedl@maastrichtuniversity.nl. The research documented in this paper was financed by the Oesterreichische Nationalbank (project number 11429), VLIR-UOS, and IOB-UA. We thank Guy Delmelle, Ligia Gómez, Miguel Alemán, Francisco Pérez, Selmira Flores and Alfredo Ruíz for interesting methodological discussions, Tania Paz Mena, Leonardo Matute, Francisco Paiz Salgado, Edna García Flores, Fátima Guevara, Silvia Martinez Arróliga and Will Tellez for support in the field work, Vanessa Castrillo and Jazmina Andino for their help in the search for sufficient coins of money, Elizabeth Campos and Manuel Bermudez of the Fondo de Desarrollo Local for offering a safe in one of their local banking offices, and the community leader Francisco Varela for his local support. We also thank colleagues at Maastricht University and the University of Antwerp for comments on the experimental design and the many participants in workshops, seminars, and conferences in Utrecht, Rome, Berlin, Nijmegen and Maastricht for their valuable remarks. We also benefited very much from comments on an earlier version of this paper by Rebecca Blank, Vincent Buskens, Simon Gächter, Jean Hagenbach, Matt Jackson, and Michael Woolcock. 


\section{Introduction}

This paper explores the interrelation between the embeddedness of individuals in networks and their pro-social behavior in the form of generosity 1 When considering the influence of networks on behavior it is important to recognize that people are simultaneously embedded in several network dimensions (or specific networks). Individuals are connected to friends, neighbors, colleagues at the workplace, business relations and so forth, and it is unlikely that these specific networks are completely overlapping. In addition, the ties creating these specific networks are likely having different contents (e.g., emotional versus rational). Different network dimensions are also important for different activities, may exhibit different structures and, therefore, may have different effects on economically relevant behavior. For instance, Coleman (1988, 1990) argues that networks that are locally dense and have high clustering are fostering pro-social behavior. Friendship networks are often of this type. On the other hand, according to Burt (1992, 2005), agents with a central position in a network are favored as they have more power and, hence, are able to pursue their own goals better. Business networks often have such central players.

In order to investigate the relation between different network dimensions and generosity we surveyed all household heads in a rural village in Nicaragua and elicited the whole network for several important network dimensions: friendship, mutual support, public activities, economic relations, neighborhood. In addition, we measured individual generosity in a controlled way, by organizing a series of dictator game experiments with the household heads. In the experiment each 'dictator' was matched with known participants from the village as well as a stranger from another village, where we use the generosity towards the latter as a proxy of the household

\footnotetext{
${ }^{1}$ Generosity is a widespread, economically and socially relevant, phenomenon. In controlled experiments it is repeatedly observed that people are willing to give up money even if the recipient is an anonymous stranger (see Camerer, 2003, chapter 2, for a survey, and Fisman et al., 2007; List, 2007; Bardslev, 2008; Carpenter et al., 2008; Konow et al., 2008, for recent evidence). This habit of giving, which is observed across nations and cultures (Henrich et al., 2005) is not only confined to experimental environments. For instance, generous behavior in the form of charity giving is an important economic factor. According to Andreoni (2008), in 2005 charitable giving by private individuals totaled about USD 200 billion in the United States. Similar figures are found in other countries around the world (cf. Andreoni, 2006). Generosity is also widely observed in every day life in the form of, e.g., neighborhood support and volunteering, and is generally perceived as a desirable habit in society.

Among economists it is now also widely recognized that networks play an important role in economic life. For instance, network effects have been shown to be important for worker productivity Bandiera et al. (2009), welfare culture (Bertrand et al., 2000), migration and labor markets (Rees, 1966; Granovetter, 1973, 1995; Montgomerv, 1991; Ioannides and Lourv, 2004; Munshi, 2003), mutual insurance (Fafchamps and Lund, 2003; De Weerdt and Dercon, 2006), informal credit markets (McMillan and Woodruff, 1999; Karlan, 2007), and international trade (Casella and Rauch, 2002).
} 
heads' general generosity. To the best of our knowledge there are only two other studies that look into the potential effects of different network dimensions on economic and social behavior. In the sociological literature Podolnv and Baron (1997) seem to be the only authors who have taken up this issue 2 In economics only Jackson et al. (2010) report network data of relationships with different contents for villages in India. Neither of these studies relates the specific network dimensions to individual behavior in a controlled way.

A main objective of our study is to examine in what way the potentially different structures related to different network dimensions and the accompanied positions of individuals in such networks influence these individuals' generosity. More specifically, we explore, first, whether network structure and network embeddedness can account for the variation observed in individual generosity and which structural characteristics of the network are important (if any). Second, we study, whether the influence of network structure and position indeed varies across networks of different social and economic dimensions. Third, we investigate, whether observable individual characteristics have explanatory power. Finally, we also explore whether individual background characteristics influence network formation itself. Finding such an effect would indicate that these characteristics affect generosity indirectly via the channel of network formation.

There are a few recent studies that are related to ours. Leider et al. (2009) and Goeree et al. (2010) also combine network elicitation with controlled experiments. The former elicited the friendship networks among students residing in two dormitories at Harvard University and let them play variants of the dictator game and a helping-game. The latter authors also elicited friendship networks and investigate dictator game giving among teenagers in an all-girls school. Brañas-Garza et al. (2010) conduct a similar study with Spanish students.

Our study goes beyond that literature in at least two important aspects. First, we conducted our research in a rural village in the Southern hemisphere. Therefore, our investigated social unit is profoundly different from the student groups investigated in the mentioned work. This is important because recently some scholars have forcefully argued that behavior of wealthy students in the Northern hemisphere is special and that it is at least questionable to generalize to populations with other backgrounds (cf. Henrich et al., 2010). Second, we elicited not only friendship ties but also a number of other network dimensions people are simultaneously embedded in. This allows us to separately analyze and compare whether and how different specific networks affect behavior. Importantly, we also elicited the friendship network which makes it possible to check if the effects of friendship ties identified among students in the U.S. and Europe

\footnotetext{
${ }^{2}$ They analyze different contents of social relations of managers first mapped by Burt (1992) and show that the implications of network structures for manager behavior are not independent of link content. (We thank Saurabh Arora for providing this information in a personal communication.)
} 
can also be found for friendship ties in a rural village in a developing country. If we find that, despite the obvious differences in the investigated population, the same network variables are important determinants of generous behavior, we would have strong suggestive evidence for the hypothesis that network effects are universally applicable.

Indeed, regarding the network effects of friendship relations we confirm the main result of the mentioned studies. Social distance matters for generosity also in our very different population. Direct friends are treated significantly more generously than people at larger distances in the friendship dimension. However, this result does not hold for any of the other specific networks. Hence, the finding that direct contacts are treated better than indirect ones is specific to friendship relations.

Another main result is that structural network variables reflecting dense embeddedness (i.e., clustering) and powerful positions (i.e., centrality) significantly affect generosity towards other network members. Other existing studies did either not explore these effects or did not find such strong influences. Importantly, the effects of structural network variables on giving behavior are not invariant across different network dimensions. In the friendship network and the economic network generosity towards village recipients increases with the centrality of the dictator and decreases with the density of her connectedness. In contrast, in the support network dictators with dense local networks are more generous but centrality plays no role. Not only the dictators' but also the recipient's network position matters differentially for the dictators' directed generosity. In the economic network and the network of social-public activities, dictators are more generous towards recipients who are densely connected. For the network of social-public activities it also holds that less central recipients are more generously treated. Interestingly, the structural network variables of recipients do not have an effect in the friendship and support networks. In summary, our results show that structural network characteristics matter for giving behavior and that these effects clearly depend on the network dimension.

Regarding observable individual characteristics we find that after controlling for network effects only gender has explanatory power. Interestingly, and in contrast to most other studies on gender effects, women are less generous than men, especially when the recipient is male. We also find that village members are treated better as well as worse than strangers, and that generosity towards village members is positively related to general generosity towards strangers. A final finding is that certain individual characteristics are indeed important determinants of tie formation in the elicited specific networks and that their influence varies across different network dimensions. This strongly suggests that the influence of observable individual characteristics on generosity runs indirectly through the network effects and that this channel differs for different specific networks. 
The rest of the paper is organized as follows. In Section 2 we describe our research design, the network elicitation procedure and report descriptive statistics regarding our investigated population and the elicited networks. It also presents the procedures applied in the dictator game experiment. Section 3 presents descriptive statistics of behavior in the dictator game, followed by regression results explaining dictator giving with observable individual characteristics, social distance and network effects. The section closes with an analysis of the determinants of link formation in the different specific networks. Section 4 summarizes and concludes.

\section{Research Design, Network Characteristics, and Experimental Procedures}

We collected data from a whole real existing long-grown social unit that profoundly differs from formerly investigated Northern high-school and student populations (cf. Leider et al., 2009; Goeree et al., 2010). Specifically, we gathered data of household heads of an entire village in rural Nicaragua. The investigation of such a social unit is important for several reasons. First, it delivers very different and more varied individual characteristics than relatively homogeneous student populations do. This increases the likelihood that socio-economic characteristics can contribute to the explanation of variation in behavior and, thus, also provides an important robustness test for any eventually detected social distance and network effects. Second, it reflects the social structure of a naturally grown and long-lasting small-scale society. In such societies social ties are potentially of life-long importance and likely to be more pronounced than in units of associations that have knowingly only a temporary character. This might increase the likelihood of detecting network effects, which were not found in the mentioned studies on homogeneous and temporary associations. Importantly, social units as the one studied here are not rare special cases. In fact, most rural people in the Southern hemisphere live in such small-scale societies. Third, it allows us to explore different dimensions of networks that may exist within a social unit. One reason why other studies only investigated friendship networks is that there are little other important social relations among students. In contrast, in our long-grown social unit people have all sorts of important social ties. Next to friendship ties there exist, among others, business relations, histories of giving and receiving help, and simple neighborhood ties. This allows us to explore whether different network dimensions have differential impacts on giving behavior.

In the data gathering process we, first, organized a questionnaire study for collecting a number of societal characteristics. Second, we elicited different dimensions of social and economic ties among (almost) all household heads by means of a network survey. Third, after the survey we conducted a series of dictator game experiments, measuring generosity between household heads 
in the village as well as toward strangers outside the village. At the end of the experiment all participants answered a post-experimental questionnaire. The socio-economic questionnaire and network elicitation was carried out in four consecutive days. Immediately thereafter the whole experiment was conducted in a single day, which minimized potential spill-over and contagion effects.

In the following we further describe the main elements of our research design and report important socio-economic facts and characteristics of the elicited networks. For detailed information beyond that reported in this section we refer the reader to Appendix A.

\subsection{Household Survey and Societal Characteristics}

With the household survey we gathered data on important economic assets (possession of land or cattle), family composition, education, age, sex, etc 3 The village consists of 66 households of which 9 are single-headed and 57 two-headed (i.e., 123 household heads in total). We gathered data of 58 households (87.9 percent) and at least 100 household heads (81.3 percent).

Table 1: Summary statistics of important socio-economic characteristics

\begin{tabular}{lccc}
\hline \hline Households & mean/percentage & st.dev. & no. of obs. \\
\hline Land (percentage of owners) & 34.48 & - & 58 \\
Land (mean in ha.) & 8.22 & 17.33 & 58 \\
Cattle (percentage of owners) & 46.55 & - & 58 \\
Cattle (mean in no. of animals) & 3.55 & 9.44 & 58 \\
Household heads & & & \\
\hline Sex (percentage male) & 49.50 & - & 109 \\
Age (mean in years) & 46.05 & 14.49 & 109 \\
Education (mean in years) & 4.13 & 3.59 & 109 \\
Residence in village (mean in years) & 33.22 & 15.63 & 100 \\
Visits to urban center (mean no. last month) & 2.07 & 3.36 & 100 \\
\hline
\end{tabular}

Table 1 shows descriptive statistics of important characteristics of the households and household heads in the village. It indicates a pronounced diversity across households as well as household heads. Only 34.48 percent of the households own land. Land possession measured in hectares is also very unequally distributed. The standard deviation is more than twice as large as the mean of 8.22 hectares. For cattle possession the figures are similar. Only 46.55 percent of all households possess any cattle, and the average number of cattle per household is 3.55 with a standard deviation of 9.44. This unequal distribution of land and cattle implies a large variation

\footnotetext{
${ }^{3}$ For more detailed geographical and economic background of the village and detailed procedures, see Appendix A.1 and A.2 respectively.
} 
in wealth across households. The variation in important individual characteristics of household heads is also considerable. About half of all interviewed household heads are female and the age varies between 21 and 86 years, with an average of 46.05 years. The average education level of the household heads, measured in number of years of schooling, is only slightly above 4 years with also quite some variation. The household heads reside in the village between only half a year and 70 years with an average of 33.22 years. Another potentially important characteristic is the frequency of contact with the urban center because it can be interpreted as a proxy for the strength of ties to people outside the village. It varies between 0 and 26 visits in the most recent month before we took the survey. In summary, we have considerable variation in socioeconomic characteristics of households and household heads, which is an important precondition for being able to explain possible variations in generosity in our experiment through individual characteristics.

\subsection{Elicitation and Properties of Networks}

An important characteristic of social interactions is that they take place in several dimensions simultaneously. People may not only be friends, but may also have ties because they support each other, engage in economic transactions, or because they are neighbors. On the other hand, these different dimensions will only partly overlap. People who do business with each other may or may not be friends, friends may or may not be neighbors, and so on. Hence, people tend to be differentially connected in the different network dimensions. Furthermore, different network dimensions carry different contents. Friendship and mutual support ties are likely of an emotional type, where the latter may also comprise forward-looking investment into social capital. One may hypothesize that these dimensions are both supportive for directed generosity. In contrast, ties trough economic transactions are based on contractual relations and probably a less fertile ground of generous behavior. Such differences in ties content and network structure make it likely that eventual network effects on generosity differ across specific network dimensions.

In order to elicit the different dimensions of relationships of all household heads in the village we adapted a survey method successfully employed by economic anthropologists and sociologists for mapping bounded networks 45 In brief, to elicit the ties of an interviewee we used a stack

\footnotetext{
${ }^{4}$ Bounded networks are networks with clearly defined boundaries, such as networks within villages and organizations, for which all members are surveyed. For a description of the method see, for instance, the documents section of Jean Ensminger's and Joseph Henrich's Roots of Sociality project web-site at http://www.hss.caltech.edu/ jensming/roots-of-sociality/docs/Social-Network-Analysis.doc

${ }^{5}$ Leider et al. (2009) used an incentivized coordination game procedure for eliciting friendship networks among Harvard students. There are two reasons why we did not adopt their elicitation method. First, most likely it would have become too complicated for our often illiterate subjects, who are not used at all to abstract exercises.
} 
of small cards representing all households in the village. Each card held the name(s) of the household head(s) of a household. For each of the cards the interviewee was first asked whether he or she knows the household and whether he or she has a "social relation of any kind" with any of the household heads. In this way we gathered data of general relations that are relations aggregating all types of social and economic interactions. If the answer to the first question was affirmative we asked for details on the content of the relation and elicited six specific network dimensions. First, friendship relations that are relations where a person calls another one a friend. Second, support relations that are relations where any type of help, e.g., small amounts of food, cash, or transport manpower, is given to or received from a person. Third, socialpublic relations that are relations brought about by public activities related to religion, political parties, the village school, sports, cooperative organization, development projects or the village committee. Fourth, economic relations that are relations resulting from an exchange of land or labor, a commercial activity, a service provision or a lending activity. In addition, we also elicited neighbor relations, that are relations between two persons who consider themselves as neighbors, and family relations with parents, brothers, sisters, and children 6.7

We succeeded to gather network data for 100 of the 123 household heads ( 81.3 percent) 8 In processing the network data we proceeded in the following way. First, as we did not explicitly capture links between members of the same household, we assume that intra-household relations between household heads exist for general relations, friendship relations, and support relations, but not for the other reported relations. The rationale for this data treatment is that household members tend to be friends and to support each other, but they are never neighbors to each other and it is unlikely that they have business-like economic relations or that they are related through social public activities. Second, for each network dimension we symmetrized the resulting adjacency matrix (i.e, the matrix representing directed ties in the population). That is, in each network dimension, for each dyad (i.e, pair of household heads), we assume that a relation exists

Second, practically it is only applicable for the elicitation of 1-dimensional networks. One of our main interests lies in capturing multiple dimensions of networks, however.

${ }^{6}$ The nature of these family relations differs from the other elicited dimensions (e.g., by its genetic determination). Therefore, and for the sake of brevity we do not report on these relations in this paper but are planning to report it elsewhere.

${ }^{7}$ We are aware of only one other data set that contains a number of different network dimensions. Jackson et al. (2010) report on a stratified survey sample (about 50 percent) of households in a number of villages in India. They elicit the dimensions Relatives, Temple Company, Hedonic, and Favors, which are similar to our family, socialpublic, friendship, and support relations, respectively.

${ }^{8}$ Of the missing 23 household heads 21 were not present in the village when we conducted the study; only two household heads refused to participate. Our success ratio is slightly higher than those of Goeree et al. (2010) and Leider et al. (2009), who report success rates of 77 and 71 percent, respectively. 
if at least one node mentions the relation. In using these so-called OR-networks throughout the analyses we follow the practices of recent network studies (cf. Leider et al., 2009; Jackson et al., 2010).

Table 2: Properties of the different networks

\begin{tabular}{lcccc}
\hline \hline & Density $^{\mathrm{a}, \mathrm{b}}$ & Centrality $^{\mathrm{a}, \mathrm{c}}$ & Clustering $^{\mathrm{a}, \mathrm{d}}$ & \\
\cline { 2 - 5 } General relation & 0.354 & 0.030 & 0.254 & $(0)$ \\
Friendship relation & 0.186 & 0.103 & 0.133 & $(0)$ \\
Support relation & 0.032 & 0.326 & 0.040 & $(2)$ \\
Social public activities & 0.039 & 0.214 & 0.085 & $(23)$ \\
Economic relation & 0.038 & 0.389 & 0.041 & $(13)$ \\
Neighbor relation & 0.052 & 0.167 & 0.054 & $(3)$ \\
\hline
\end{tabular}

Note: ${ }^{\text {a }}$ OR-networks, intra-household relations (not) counted as valid links in general, friendship, and support relations (neighbor, social public activities, and economic relations); ${ }^{\mathrm{b}}$ actual links as fraction of all possible links; ${ }^{\mathrm{c}}$ Freeman's betweenness centrality; ${ }^{\mathrm{d}}$ network clustering coefficient, number of isolated nodes in parentheses.

Table 2 shows the standard network measures density, betweenness centrality and clustering for the different network dimensions. Network density is simply given by the sum of actual ties divided by the number of all possible ties. It is not surprising that density is highest for general relations because they aggregate relations across all dimensions. Among the specific networks friendship relations are relatively dense, whereas the other networks have relatively low densities.

Betweenness centrality (Freeman, 1977, 1979) is based on the notion of the shortest path between pairs of nodes. Informally, the shortest path between two nodes $i$ and $j$ is the minimum number of links in the network necessary to reach each other. Betweenness centrality captures the idea that agents who lie on the shortest paths between many pairs of agents are relatively more central than those who lie on the shortest paths of only a few such pairs. An intuitive interpretation of betweenness centrality is that agents who are central have 'local control' over those who have to use them to reach each other (who are 'locally dependent'). The former are 'gatekeeping' the latter (cf. Wasserman and Faust, 1994). In this sense, high betweenness centrality is a necessary condition for occupying a 'broker' position in the network (Burt, 2005). Formally, let $p_{j k}(i)$ be the number of shortest paths between nodes $j$ and $k$ that pass through $i, p_{j k}$ the total number of shortest paths between nodes $j$ and $k$, and $n$ the total number of nodes in the network, then the normalized betweenness centrality $B C(i)$ of a node $i$ is given by $\left[\sum p_{j k}(i) / p_{j k}\right] /[(n-1)(n-2) / 2]$, where the sum is taken over all dyads $j k$ with $i \neq j \neq k$. On the aggregate level betweenness centrality is a measure of the distribution of agents' betweenness centrality in the network. In takes on the value 1 in the star network, the most centralized 
network possible. In a star network there is one center node through which all shortest paths between any periphery nodes run. The measure takes on the value 0 in case of the complete network, where everybody is linked with everybody else and, hence, all nodes are equally central in the betweenness sense.

Table 2 shows that centrality is highest in the network of economic relations, followed by support networks and networks through social public activities. Interestingly, friendship relations are relatively low in centrality indicating that friendship ties run through a relatively equal number of people. The low centrality of neighbor relations suggests that the housing village structure is not star shaped.

In the sociological literature, network closure (i.e., clustering) is considered important for sustaining cooperation, trust, and pro-social behavior in general (cf. Coleman, 1988, 1990). Clustering coefficients are measures that reflect the extent to which two different nodes that are linked to another common node are linked to each other. More formally, our clustering coefficient is based on the notion of triples. A triple consists of three nodes that are connected by either two (open triple) or three links (closed or transitive triple; sometimes also called triangle). The network clustering coefficient reported in Table 2 is defined as the ratio of the number of closed triples over the number of all (open and closed) triples in the network (cf. Newman, 2003) 9

The last column in Table 2 reports the network clustering coefficient for the general relations network as well as the specific network dimensions. It shows that also with respect to clustering the specific networks differ substantially. Clustering is highest for friendship relations and lowest for support and economic relations. The low clustering in the economic network in combination with the high centrality and low density implies that there are only a few transitive relations and only a few nodes that are economically important for the villagers. Friendship networks are characterized by relatively high density and clustering but low centrality. Hence, in the sense of Coleman (1990), they seem ideal for sustaining generosity.

The discussed network measures clearly indicate that networks differ across the different network dimensions. An alternative way of inferring differences between different network dimensions is by examining their overlap. Table 3 shows the percentage of overlap between any network dimension, measured at the dyad level. It indicates that the pair-wise overlap between different network dimensions never reaches 50 percent. Furthermore, the overlaps between any two dimensions widely differ and are highly asymmetric. Specifically, for any network dimension a dyadic relationship often implies a friendship relation (cf. column Friendship in Table 3) but not vice versa (cf. row Friendship in Table 3). There is an interesting and intuitive overlap between support and neighbor relations. About a quarter of all support relations is between

\footnotetext{
${ }^{9}$ For completeness we report the number of open and closed triples in Appendix B.2 Table B.2
} 
Table 3: Overlap of different network dimensions (in percent)

\begin{tabular}{lccccc}
\hline \hline & Friendship & Support & Neighbor & Social-public & Economic \\
\cline { 2 - 6 } Friendship & 100 & 6.38 & 12.67 & 9.44 & 8.93 \\
Support & 42.93 & 100 & 25.54 & 10.33 & 15.76 \\
Neighbor & 40.15 & 12.02 & 100 & 5.12 & 5.37 \\
Social-public & 40.34 & 6.55 & 6.90 & 100 & 5.17 \\
Economic & 36.75 & 10.25 & 7.42 & 5.30 & 100 \\
\hline
\end{tabular}

Note: In the table inclusion runs from the row relations to the column relations (for instance, only 6.38 percent of the friendship ties are also support ties, but 42.93 percent of the support ties are also friendship ties). Hence, the overlap between any two dimensions does not need to be symmetric. Possible intrahousehold links between household heads are ignored.

neighbors. On the other hand, only about 12 percent of the neighbor relations are also support relations. There exists also a large discrepancy between friendship ties and economic relations. On the one hand, more then 36 percent of all economic relations are with friends, but only about 9 percent of all friendship ties also have an economic nature. In summary, the different network dimensions only show a partial and highly asymmetric overlap and they strongly differ in the network measures density, centrality and clustering. Figure 1 visualizes the differences between the friendship network and the economic network. A visualization of all elicited networks can be found in Appendix B.4.

The discussed differences in the network structures across the different network dimensions are a result of differences in relations at the dyad level. Therefore, we expect to see these differences being reflected when relating them to giving behavior in the dictator games, which also takes plays at the dyad level.

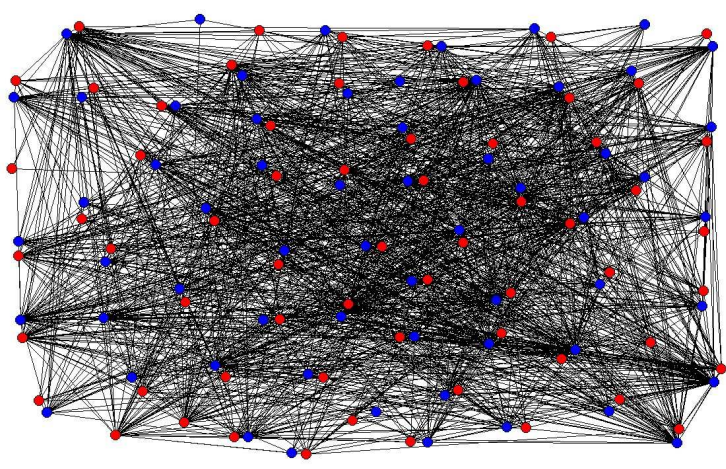

(a) Friendship network

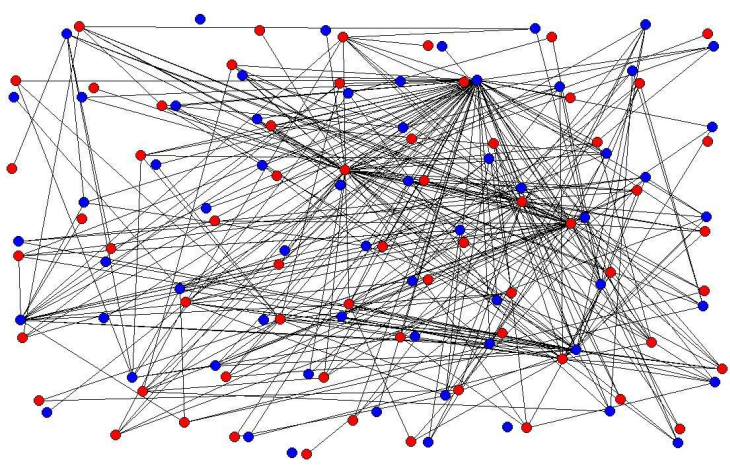

(b) Economic network

Note: Household heads of the same household are placed next to each other.

Figure 1: Friendship network and economic network 


\subsection{The Dictator Game Experiment: Design and Procedures}

Each participating household head played six subsequent dictator games with different recipients. The experimenter explained each participant in the role of a dictator that he or she would sequentially receive six small cylinder-boxes each containing 20 coins of one Córdoba, $\mathrm{c} \$$ (the Nicaraguan currency), which he or she could share with one other person. For each dictator the first recipient was a stranger, that is, an unknown person from another village in the region. The five subsequent recipients were randomly selected village members. The random selection involved the dictator drawing cards out of a bag containing all 123 household heads. The name of a recipient was drawn only after the dictator had finished the previous distribution decision. Dictators were informed of the procedures before they made any decision and, hence, knew that their maximum possible earnings would be $\mathrm{c} \$ 120,-$ (USD 6.70 at the time of the experiment), which corresponded to more than a two days average income in Nicaragua 10

We wanted to conduct the experiment with all households in the village and had to take care that the chance of contagion and spill-over effects was minimized. Therefore, only one household head per household was allowed to participate as a dictator. In case of a two-headed household it was randomly determined who was asked to participate. We did not exclude participation of the other household head in the role of receiver, but ensured that heads of the same household were not matched as a dictator-receiver pair. In total 57 household heads participated as dictators 11

We organized the experiment in a decentralized way, by having Nicaraguan research assistants individually visiting each participant at his or her home to conduct the experiment 12 To minimize behavioral biases due to potential post-experimental side payments or social pressure we implemented a one-way anonymity design. Each dictator was clearly made aware that, although he or she knows the identity of the recipient, the recipient does not know and also will not get to know who has distributed the money. When delivering the money to recipients we did neither reveal the identity of the dictators, nor did we inform them about how many dictators

\footnotetext{
${ }^{10}$ We also considered to pay out only one randomly chosen decision, but decided against it because the explanation and implementation of a relatively abstract randomization device would have been very time consuming and may have also raised suspicion in our subjects who were not used to experiments.

${ }^{11}$ We targeted all 66 households, but of nine households no household heads were present at the day of the experiment.

${ }^{12}$ In doing so we deviated from the often used protocol in studies with participants in small-scale societies, where experiments are conducted centralized at a public spot (e.g., Cardenas et al., 2000; Henrich et al., 2004). The reason not to use this standard is that we see some potential problems regarding experimental control coming along with it. First, it is virtually impossible to avoid self-selection because some people are clearly more inclined to participate in public events than others. Second, during such gatherings mutual influence among participants is hard to control.
} 
had participated. Dictators and recipients did also not learn anything about others earnings. All this was known by the dictators when they made their decisions.

To minimize experimenter effects due to the assistant's presence we employed the following three precautionary measures. First, all decisions were made in full privacy. As a rule participants went inside their house or to a separate room when making a decision. If this was not possible the assistant turned his or her back when the dictator was handling the coins. The dictators were also instructed not to make any comments about their decisions. Second, after having taken the coins they wanted to keep from the box, dictators had to fill the box with metal rings. This ensured that the weight of the box remained constant irrespective of the amount of coins taken out. Third, after each decision the box was sealed with tape. The decisions were recorded by the assistants' supervisor (one of the principal investigators) who did not have any interaction with the participants. The dictators were aware of these procedural details before they made any decisions 13

An important aspect in experiments is that participants trust the researchers. This is especially true in the field and when participants are not used to experiments. Therefore, to build trust, we first conducted the household and network survey. This ensured that, when conducting the experiment, the research assistants were already known to the local people. Another important element was the support of the well-respected local community leaders, who presented our team to each household and asked people to cooperate. After having finished the surveys, which took four days, we immediately organized the experiment. By conducting the whole experiment in only one day we minimized possible contagion and spill-over effects. Indeed, from the debriefing we know that 94.5 percent of the participants did not talk about the experiment with other village members who had already participated before. In addition, the research assistants were asked to make a subjective evaluation about the participant's dedication, trust and understanding of the experiment. We did not notice any problems that could have affected the dictators' decisions.

\section{Empirical Results - Generosity and Networks}

In this section we report first on dictators' behavior in the experiment. Thereafter, we explore with descriptive and regression analyses whether and how individual and network characteristics are related to giving behavior. Finally, we investigate how individual characteristics influence network formation and, hence, indirectly giving behavior.

\footnotetext{
${ }^{13}$ For more details we refer the reader to the experimental instructions in Appendix A.3 A video showing a typical decision situation in the experiment can be found here: download and play video
} 


\subsection{Generosity in the Dictator Game}

Figure 2a shows the distribution of coins given to village recipients taking all 285 decisions into account. It shows a dominant mode at the equal split of 10 coins and a second (much smaller) mode at the selfish decision of 0 coins. What is intriguing is the relatively large share of decisions where recipients received more than 50 percent of the endowment of 20 coins. The average share left to recipients is with 48 percent (9.6 coins) also higher than what is mostly observed in laboratory dictator games. The relatively small size of the community where our experiment was conducted together with the fact that dictators got to know the names of the recipients when making their decisions may account for this 'super fair' behavior. Indeed, Bohnet and Frev (1999) showed that revealing the identity of the recipient significantly increases dictator giving and Henrich et al. (2005) also observe 'super fair' proposals in ultimatum game experiments in some of their investigated small-scale societies.

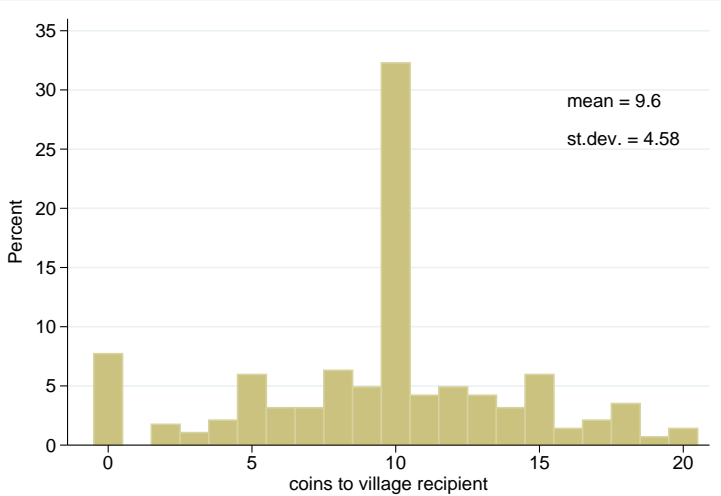

(a) Village recipient

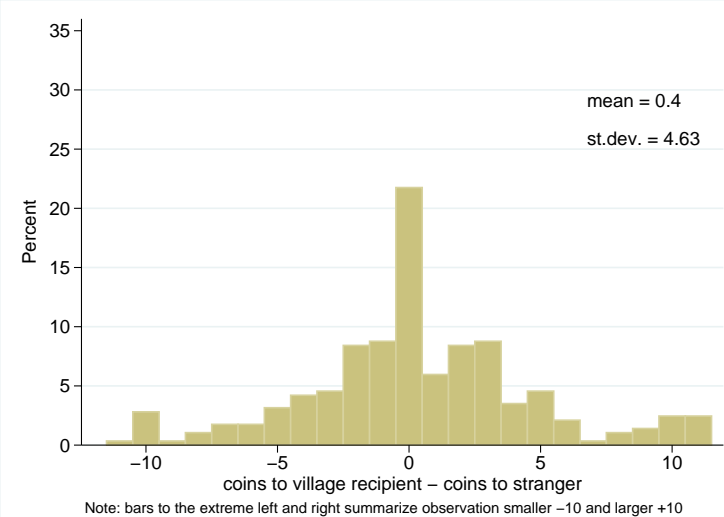

(b) Difference with stranger

Figure 2: Dictator game giving

Besides the five distribution decisions regarding different village recipients our dictators also had to make a decision regarding a stranger in another village. We consider this dictator giving to the stranger as 'baseline' or 'general' generosity (for a similar approach, see Leider et al., 2009). On average 9.2 coins (46 percent) are left for the stranger. Although, this is only little less than the average left for village recipients, it does not imply that village recipients and strangers were treated similarly. Actually, quite the contrary happened. Figure 2b shows the distribution of differences in coins left to village recipients and strangers. Although, there is a mode at zero, in the large majority of cases (78.2 percent) dictators give different amounts to village recipients and strangers. In addition, the distribution shows an intriguing symmetry indicating that village members receive as often less than strangers as they receive more. Thus, social proximity in terms of living in the same village does not necessarily imply better treatment than any stranger 
would receive. This observation casts new light on the idea of and evidence on in-group favoritism (see, e.g., Efferson et al., 2008; Chen and Li, 2009). In particular, it indicates that favoritism is not per-se towards own group members but only towards specific members in the own group. In addition, it also suggests that social ties are not necessarily positive but may have a negative load as identified by van Dijk et al. (2002).

We also find quite some variation in giving behavior within the same dictator. Only six dictators gave the same amount to all village members. Five of them chose the equal split and one left 8 coins to each recipient. Only four of them gave also the same amount to the stranger.

\subsection{Explaining Patterns of Generosity - Individual Characteristics and Net- work Effects}

Although the correlation between giving to the stranger and average (per dictator) giving to village recipients is positive and significant (Pearson correlation coefficient $=0.674, p<0.001$, two-sided test), the large variation in giving to these distinct groups of recipients indicates that general generosity alone is insufficient to explain the complex pattern of giving behavior. In this section we examine whether observable individual characteristics, network structures and network positions can account for the observed pattern in generosity directed towards village members.

We expect differential influences of the different network dimensions on directed generosity and, thus, investigate the individual and network effects on dictator giving separately for general relations as well as the various specific relations. Table 4 shows descriptive statistics of dictator giving as a function of social geodesic distance (i.e., the shortest path) between the dictator and the recipients for the different relations. Although, absolute differences are small the figures reported in the table clearly indicate that dictator giving differs across social distances within a network dimension as well as across network dimensions. However, there are also some similarities. For all relations (except neighbors) dictator giving to directly linked recipients (i.e., at distance 1) is more generous than giving to strangers. In addition, in most network dimensions there is also a social distance effect in that direct relations receive more than indirect relations. This effect is most pronounced for friendship and support relations but absent in neighbor and economic networks. Interestingly, except for the support network, there seems to be no clear monotonic relationship between generosity and social distance beyond distance 2 .

The reported averages may hide considerable heterogeneity in giving behavior, though. Indeed, the standard deviations depicted in Table 4 reveal that dictator giving strongly varies across social distances and network dimensions. To pin down determinants that can explain these variations we conduct regression analyses. In particular, we estimate regression models that 
Table 4: Dictator giving and social distance in different networks

\begin{tabular}{|c|c|c|c|c|c|c|}
\hline \multirow[b]{2}{*}{ Network dimension } & \multirow[b]{2}{*}{ Stranger } & \multicolumn{5}{|c|}{ Social geodesic distance of } \\
\hline & & 1 & 2 & 3 & 4 & $\geq 5$ \\
\hline \multirow[t]{3}{*}{ General } & 9.18 & 10.07 & 9.29 & 9.00 & & \\
\hline & $(5.43)$ & $(4.40)$ & $(4.70)$ & - & & \\
\hline & {$[57]$} & {$[114]$} & {$[170]$} & {$[1]$} & & \\
\hline \multirow[t]{3}{*}{ Friendship } & 9.18 & 10.80 & 9.26 & 9.83 & & \\
\hline & $(5.43)$ & $(4.80)$ & $(4.52)$ & $(4.30)$ & & \\
\hline & {$[57]$} & {$[54]$} & {$[207]$} & {$[24]$} & & \\
\hline \multirow[t]{3}{*}{ Support } & 9.18 & 11.00 & 9.90 & 9.78 & 9.66 & 8.66 \\
\hline & $(5.43)$ & $(5.72)$ & $(5.25)$ & $(4.84)$ & $(4.24)$ & $(3.59)$ \\
\hline & {$[57]$} & {$[12]$} & {$[48]$} & {$[95]$} & {$[74]$} & {$[56]$} \\
\hline \multirow[t]{3}{*}{ Neighbor $^{\mathrm{a}}$} & 9.18 & 9.15 & 10.20 & 9.44 & 9.87 & 5.80 \\
\hline & $(5.43)$ & $(3.98)$ & $(4.58)$ & $(4.44)$ & $(4.66)$ & $(5.53)$ \\
\hline & {$[57]$} & {$[20]$} & {$[80]$} & {$[112]$} & {$[63]$} & {$[10]$} \\
\hline \multirow[t]{3}{*}{ Social-public ${ }^{\mathrm{a}}$} & 9.18 & 10.35 & 10.24 & 8.72 & 10.05 & 9.64 \\
\hline & $(5.43)$ & $(4.69)$ & $(4.52)$ & $(4.83)$ & $(3.99)$ & $(4.42)$ \\
\hline & {$[57]$} & {$[17]$} & {$[84]$} & {$[89]$} & {$[20]$} & {$[75]$} \\
\hline \multirow[t]{3}{*}{ Economic $^{\mathrm{a}}$} & 9.18 & 9.67 & 9.98 & 9.08 & 9.40 & 9.59 \\
\hline & $(5.43)$ & $(5.33)$ & $(4.65)$ & $(4.74)$ & $(2.95)$ & $(4.54)$ \\
\hline & {$[57]$} & {$[15]$} & {$[121]$} & {$[83]$} & {$[20]$} & {$[46]$} \\
\hline
\end{tabular}

Note: For each network dimension the first row shows the average number of coins left to the stranger and the village recipients at different distances, respectively; standard deviations in parentheses; number of observations in brackets; a possible intra-household links between household heads are ignored.

incorporate observable individual characteristics of dictators and recipients, the social distances between them, dictators' general generosity, and (local) network characteristics. Specifically, we estimate the following OLS model 14

$$
Y_{i j}=\alpha+\beta \boldsymbol{X}_{i j}+e_{i j}
$$

where $Y_{i j}$ denotes the amount of coins dictator $i$ gave to recipient $j, \alpha$ is the intercept, $\boldsymbol{X}_{i j}$ denotes the vector of explanatory variables which we will discuss in detail below, and $e_{i j}$ is an error term. In the experiment, each dictator made giving decisions regarding five different village recipients. Due to the presence of specific factors common to all observations involving a particular dictator, our observations may not be assumed to be independent, implying that $E\left[e_{i j}, e_{i k}\right] \neq 0$ for all $k$. Further, different dictators may have been asked to make a distribution

\footnotetext{
${ }^{14}$ We also estimated a Tobit regression model with lower censoring set at zero. Due to the few censored observations (see Figure 2a) outcomes do not significantly differ from the reported results.
} 
decision with the same recipient, implying that $E\left[e_{i j}, e_{k j}\right] \neq 0$ for all $k$. To correct standard errors for these dependencies we apply clustering on both dimensions separately (for a formal discussion of this issue, see e.g., Fafchamps and Gubert, 2007; Cameron et al., 2010).

Our strategy in estimating individual and network related determinants of dictator giving is the following. In a first model we include individual characteristics that are likely to influence dictator giving as explanatory variables. In a second model we control for general generosity, measured by the number of coins given to the stranger. Finally, in a third and fourth model, we add social distance and two structural network variables related to closure (Coleman, 1988) and brokerage (Burt, 2005) as explanatory variables for directed generosity.

In Model 1 we control for gender, age and wealth, for both the dictator and the recipient, because previous studies have found some evidence that these traits influence pro-social behavior (see, e.g., Eckel and Grossman, 1998; Andreoni and Vesterlund, 2001; Croson and Gneezv, 2009, on gender, List, 2004; Egas and Riedl, 2008, on age, and Eckel and Grossman, 1996; Brañas-Garza, 2006; Cappelen et al., 2008, on wealth). In addition, we also control for the level of education, years of residence in the village, and the frequency of contact with the nearest urban center. We also include the differences in these characteristics between the dictator and the recipient as explanatory variables, in order to capture potential homophily effects. Homophily, i.e. the tendency to join up disproportionately with similar people, is widely documented in the sociological literature (see, e.g., McPherson et al., 2001) and it seems not unlikely that people with similar characteristics are more generous to each other.

In the regression we take female dictator giving to male recipients as the benchmark. The variables Male $\rightarrow$ Female, Male $\rightarrow$ Male, and Female $\rightarrow$ Female, are dummy variables for the remaining dictator-recipient combinations, where the first (second) term indicates the gender of the dictator (recipient). We control for the age of the dictator $\left(A_{g} e_{-} D\right)$ and the absolute difference in age between the dictator and the recipient $\left(A g e_{-} \Delta\right)$. In a similar way, we also control for the education level of the dictator (Education_D) and the absolute difference in education between the dictator and the recipient (Education_ $\Delta$ ), both measured in years of schooling; the dictator's years of residence in the village (Residence_D) and its absolute difference between the dictator and the recipient (Residence_$\Delta$ ); and the dictator's frequency of contact with the nearest urban center (Urban_D), measured as the number of visits in the most recent month before the interview, and its absolute difference between the dictator and the recipient (Urban_ $\Delta$ ).

Clearly, the wealth of the involved agents may play an important role in dictator giving. We control for this by using dummy variables indicating whether the household of the dictator and the recipient own cattle and land, respectively 15 In the regressions we take rich households, that

\footnotetext{
${ }^{15}$ In the region where the village is located both cattle and land are the most important economic assets and good
} 
is, those where both the dictator and the recipient household own cattle and land, respectively, as benchmarks. The variables Cattle $\rightarrow$ NoCattle, NoCattle $\rightarrow$ Cattle, and NoCattle $\rightarrow$ NoCattle are dummy variables for the dictator-recipient pairs where the dictator household owns cattle but the recipient household does not, the dictator household does not own cattle but the recipient household does, and both households do not own cattle, respectively. The variables for land are defined analogously and denoted by Land $\rightarrow$ NoLand, NoLand $\rightarrow$ Land, and NoLand $\rightarrow$ NoLand. In addition, we also control for whether the decision number in the sequence of the decisions of a dictator affects giving by including decision fixed effects (Decision\#).

In Model 2, we add the amount of coins given to the stranger (GiveStranger) as explanatory variable. In this way we isolate the effect of general generosity on directed generosity. We expect that general generosity positively affects directed generosity, but that this relation is not oneto-one. In Model 3, we study the role of social (geodesic) distance between the dictator and the recipient by adding a dummy variable (Distant) that takes value 0 when the dictator and recipient are directly linked, and 1 otherwise 16 The existing studies on student friendship ties found a positive effect of social closeness on directed generosity. Here we explore whether this effect can also be found in our very different subject pool, and whether it carries over to specific networks that are not based on friendships.

Finally, in our Model 4, we add more sophisticated structural network variables that may influence directed generosity but have not been systematically studied before. First, according to Coleman (1990) closure (i.e., clustering) facilitates pro-social behavior. Closure is a measure for how densely a node is embedded in his or her local network. Practically it is defined as the extent to which any two nodes who are linked to a common node are also linked to each other. Therefore, to explore the effect of the level of closure around dictators and recipients on generosity, we add, for dictators and recipients separately, a variable defined as the number of transitive relations of length 3 (i.e., triangles) they are embedded in. The variables are denoted Closure_D and Closure_ $R$ for dictators and recipients, respectively. Figure 3 illustrates these variables. Based on Coleman's (1990) argument we expect a positive relationship between Closure_D and dictator giving. Whether a dictator will also give more to a recipient who is embedded in a dense cluster is less clear. On the one hand, recipients who are embedded in dense clusters may be viewed as pro-social, which could trigger higher dictator giving to such recipients. On the other hand, it is

proxies for the actual wealth of a household. We use dummy variables because more than half of the households does not own any cattle and almost two-thirds does not own land.

${ }^{16}$ To test the robustness of the regression results concerning this discrete specification of closeness in the network, we also estimated an alternative continuous specification. There we replaced the dummy with the inverse squared distance. All regression results reported below are robust with respect to this alternative specification; see Table B.3 in Appendix B.3. 


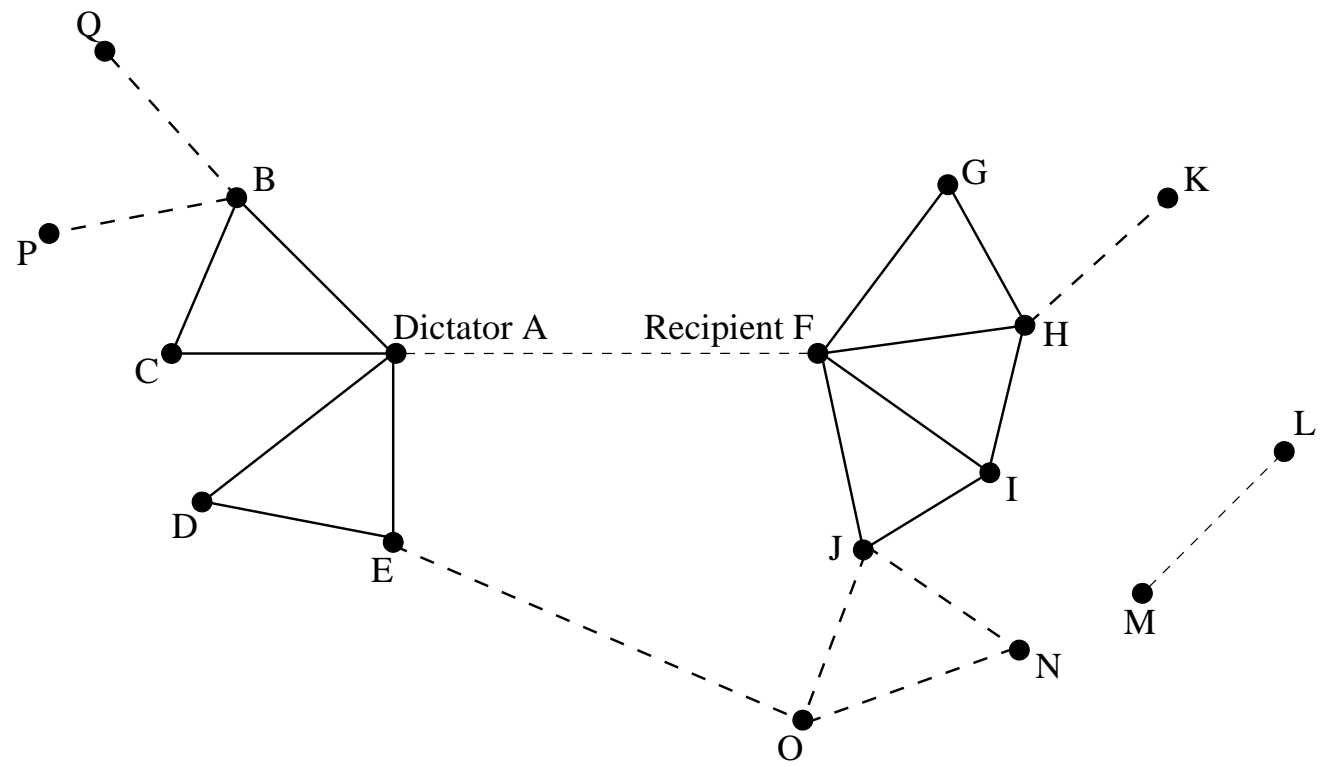

Note: In the figure all lines represent ties among individuals indicated by letters A through Q. The solid lines originating at Dictator $\mathrm{A}$ and Recipient $\mathrm{F}$ indicate the transitive relations of length 3 (triangles) of these individuals. In the example $C l o s u r e \_A=2$ and $C l o s u r e \_F=3$.

Figure 3: Illustration of the regression variables $C l o s u r e \_D$ and $C l o s u r e \_R$

also perceivable that more isolated recipients are viewed as more needy, which may also induce higher dictator giving. Therefore, we have a priori no clear hypothesis for the sign of Closure_R.

Second, Burt (1992, 2005) argues that an agent can pursue her self-interest better if she can control many other nodes because they have to use her as a 'broker' to reach each other (cf. our discussion in Section 2.2 on betweenness centrality). To examine if there is an influence of network brokerage on directed generosity in the network we add the variables Centrality_D and $C_{e n t r a l i t y} R$ which are the normalized betweenness centrality measures for the dictator and recipient, respectively. Based on Burt's (2005) arguments we expect that for dictators higher centrality is associated with less dictator giving. We also hypothesize that more central recipients are receiving higher amounts than less central ones, because betweenness centrality is likely associated with status and probably power in the village 17

An important aspect of our study is that we have elicited data for a general as well as various specific networks. When comparing results across the different network dimensions our null hypothesis is that the individual and network effects do not differ. Alternatively, because the network structures differ and the ties carry a very different content, one may expect differential influences of the network variables on directed generosity.

\footnotetext{
${ }^{17}$ One may argue that a positive effect of centrality on directed generosity could be an indirect result of being more generous in general, because this may lead to having more links (e.g., friends) and, hence, to a more central position in the network. Note, however, that we avoid this issue by controlling for general generosity (GiveStranger) in the regressions.
} 
Table 5 shows the regression results of all four models for the network of general relations. The results for model 1, where only observable individual characteristics and decision fixed effects are taken into account, show a strong and probably surprising gender effect. In our sample female dictators give significantly less to male village recipients than male dictators give to male and female recipients. This is in stark contrast to other studies on gender and generosity which report that women tend to be more generous than men (see, e.g., Eckel and Grossman, 1998; Konow et al., 2008 and Croson and Gneezv, 2009, for a recent survey). The coefficients of the variables Male $\rightarrow$ Female and Male $\rightarrow$ Male show that both, female and male, recipients receive 2.4 and 2.9 coins, respectively, more from male dictators than male recipients receive from female dictators. At the same time female dictators also tend to give more to female recipients than to male recipients, indicating that not only the dictator's gender affects giving but also the gender of the recipient. This gender effect is robust across all model specifications (see Table 5 models $2-4)$.

Age, education and duration of residence in the village do not exert any significant influence on dictator giving. The frequency of contact with the urban center increases dictator giving, which is consistent with the finding of Henrich et al. (2005) that stronger market integration tends to foster pro-sociality. Interestingly, if dictator and recipient differ in the frequency of contact with the urban center dictator giving decreases. Yet, a larger Urban_D could be related to a larger perceived or actual proximity to strangers and a larger Urban_ $\Delta$ with a larger social distance between dictator and recipient. If this is the case, the significant results for these variables may not be robust. A preview of Models 2 and 3 in Table [5] indeed reveals that adding the explanatory variables capturing general generosity (GiveStranger) and social distance (Distant) nullifies these urban contact effects. Some of the wealth variables show interesting and intuitive (marginally) significant effects. Poor dictators, those who do not own cattle, give about 2 coins less to recipients than rich dictators, who own cattle, give to rich recipients. However, also these wealth effects turn out not to be robust when controlling for general generosity, social distance and other network effects.

Model 2 shows a positive relation between general generosity (GiveStranger) and directed generosity towards village members. Dictators who give one coin more to the stranger give on average a little less than half a coin more to recipients in the network. The results for this variable in Models 3 and 4 also show that it is a robust effect. Note also, that adding general generosity as an explanatory variable makes the coefficients of all observable characteristics - except gender — statistically insignificant. Hence, even the widely varying individual characteristics in our sample do not add to the explanation of the inter-individual variation in directed generosity. 
Table 5: Determinants of directed generosity in the general relations network

\begin{tabular}{|c|c|c|c|c|c|c|c|c|}
\hline \multirow[b]{4}{*}{ Male $\rightarrow$ Female } & \multicolumn{8}{|c|}{ Dependent variable: Coins given to village recipient } \\
\hline & \multirow{2}{*}{\multicolumn{2}{|c|}{$\begin{array}{l}\text { Only individual } \\
\text { characteristics } \\
\text { Model } 1\end{array}$}} & \multirow{2}{*}{\multicolumn{2}{|c|}{$\begin{array}{c}\text { Giving to } \\
\text { stranger added } \\
\text { Model } 2\end{array}$}} & \multirow{2}{*}{\multicolumn{2}{|c|}{$\begin{array}{c}\text { Social distance } \\
\text { added } \\
\text { Model } 3\end{array}$}} & \multirow{2}{*}{\multicolumn{2}{|c|}{$\begin{array}{c}\text { Network variables } \\
\text { added } \\
\text { Model } 4\end{array}$}} \\
\hline & & & & & & & & \\
\hline & $2.385^{* *}$ & $(1.173)$ & $2.363^{* * *}$ & $(0.843)$ & $2.387^{* * *}$ & $(0.850)$ & $3.059^{* * *}$ & $(1.128)$ \\
\hline Male $\rightarrow$ Male & $2.873^{* *}$ & $(1.197)$ & $2.794^{* * *}$ & $(0.887)$ & $2.573^{* * *}$ & $(0.908)$ & $3.089^{* * *}$ & $(1.060)$ \\
\hline Female $\rightarrow$ Female & $1.056^{*}$ & $(0.619)$ & $1.296^{* *}$ & $(0.617)$ & $1.253^{* *}$ & $(0.632)$ & $1.411^{*}$ & $(0.824)$ \\
\hline$A g e_{-} D$ & 0.049 & $(0.063)$ & 0.049 & $(0.043)$ & 0.049 & $(0.042)$ & 0.042 & $(0.043)$ \\
\hline Age_A & -0.030 & $(0.022)$ & -0.002 & $(0.023)$ & -0.001 & $(0.022)$ & 0.002 & $(0.020)$ \\
\hline Education_D & 0.004 & $(0.206)$ & 0.015 & $(0.135)$ & 0.010 & $(0.133)$ & 0.042 & $(0.140)$ \\
\hline Education_s & 0.056 & $(0.079)$ & -0.029 & $(0.074)$ & -0.033 & $(0.074)$ & -0.050 & $(0.087)$ \\
\hline Residence_D & -0.064 & $(0.044)$ & -0.039 & $(0.030)$ & -0.042 & $(0.030)$ & -0.032 & $(0.027)$ \\
\hline Residence $\Delta$ & 0.007 & $(0.025)$ & -0.008 & $(0.022)$ & -0.003 & $(0.022)$ & -0.006 & $(0.023)$ \\
\hline Urban_D & $0.371^{* *}$ & $(0.182)$ & 0.128 & $(0.136)$ & 0.125 & $(0.134)$ & 0.069 & $(0.150)$ \\
\hline Urban_s & $-0.161^{* * *}$ & $(0.037)$ & -0.078 & $(0.050)$ & -0.083 & $(0.051)$ & -0.073 & $(0.051)$ \\
\hline Cattle $\rightarrow$ NoCattle & -0.465 & $(0.764)$ & -0.352 & $(0.614)$ & -0.277 & $(0.612)$ & -0.205 & $(0.629)$ \\
\hline NoCattle $\rightarrow$ Cattle & $-2.005^{*}$ & $(1.147)$ & -0.991 & $(0.710)$ & -0.977 & $(0.724)$ & -0.554 & $(0.769)$ \\
\hline NoCattle $\rightarrow$ NoCattle & $-1.737^{*}$ & $(1.025)$ & -0.600 & $(0.888)$ & -0.637 & $(0.895)$ & -0.337 & $(0.819)$ \\
\hline Land $\rightarrow$ NoLand & -0.476 & $(1.110)$ & -0.444 & $(0.869)$ & -0.333 & $(0.921)$ & -0.213 & $(0.916)$ \\
\hline NoLand $\rightarrow$ Land & -1.096 & $(1.560)$ & -0.564 & $(1.004)$ & -0.464 & $(1.011)$ & -0.656 & $(1.038)$ \\
\hline NoLand $\rightarrow$ NoLand & -1.216 & $(1.402)$ & -0.596 & $(1.019)$ & -0.540 & $(1.027)$ & -0.822 & $(1.006)$ \\
\hline Distant & & & & & $-0.827^{*}$ & $(0.461)$ & $-0.938^{*}$ & $(0.520)$ \\
\hline Closure_D & & & & & & & -0.003 & $(0.003)$ \\
\hline Centrality_D & & & & & & & 1.436 & $(1.214)$ \\
\hline Closure_R & & & & & & & 0.001 & $(0.001)$ \\
\hline Centrality_R $R$ & & & & & & & -0.470 & $(0.522)$ \\
\hline GiveStranger & & & $0.474^{* * *}$ & $(0.086)$ & $0.474^{* * *}$ & $(0.086)$ & $0.452^{* * *}$ & $(0.086)$ \\
\hline Decision $\#^{\mathrm{a}}$ & \multicolumn{2}{|c|}{ n.s. } & \multicolumn{2}{|c|}{ n.s. } & \multicolumn{2}{|c|}{ n.s. } & \multicolumn{2}{|c|}{ n.s. } \\
\hline Constant & $9.450^{* * *}$ & $(3.458)$ & 3.762 & $(3.025)$ & 4.301 & $(2.891)$ & $4.799^{*}$ & $(2.903)$ \\
\hline $\mathrm{R}^{2}$ & \multicolumn{2}{|c|}{0.1691} & \multicolumn{2}{|c|}{0.4313} & \multicolumn{2}{|c|}{0.4382} & \multicolumn{2}{|c|}{0.4498} \\
\hline F-statistics & \multicolumn{2}{|c|}{3.07} & \multicolumn{2}{|c|}{9.45} & \multicolumn{2}{|c|}{9.12} & \multicolumn{2}{|c|}{8.62} \\
\hline Prob $>F$ & \multicolumn{2}{|c|}{0.0000} & \multicolumn{2}{|c|}{0.0000} & \multicolumn{2}{|c|}{0.0000} & \multicolumn{2}{|c|}{0.0000} \\
\hline No. of obs. & \multicolumn{2}{|c|}{273} & \multicolumn{2}{|c|}{273} & \multicolumn{2}{|c|}{273} & \multicolumn{2}{|c|}{273} \\
\hline
\end{tabular}

Note: $^{* * *},{ }^{* *},{ }^{*}$ indicate two-sided significance levels at 1,5 , and 10 percent, respectively; ${ }^{\text {a }} \ldots$ decision fixed effects are not significant (n.s.); robust standard errors (in parentheses) are obtained by means of two-way clustering at the level of dictators (57 clusters) and recipients (91 clusters). 
The coefficient estimate of the variable Distant in Model 3 shows that there is a marginally significant negative effect of not being directly linked to a recipient. Recipients who are further than one link away from the dictator receive on average almost one coin less than recipients who are directly connected. Model 4 shows that this social distance effect is robust to the addition of the structural network variables closure and centrality. The network variables themselves are all insignificant, however (Table 5] Model 4). These insignificances are likely due to the little variation these variables show across nodes in the general relations network, which is relatively dense and where almost all nodes are less than three steps apart (cf. Table 4).

Existing studies report mostly insignificant effects of structural network variables in friendship networks of students (cf. Leider et al., 2009; Brañas-Garza et al., 2010; Goeree et al., 2010). This, together with our result of insignificant effects in the general relations network, makes it a priori unlikely that we will detect any network effects in our specific networks. In the following, we present the estimation results for each specific network separately, where we focus on the full fledged model (Model 4). Table [6 shows the regression results for the friendship, support, social-public activities, and economic network. The results shown in the table reveal four main insights. First, gender and general generosity are important explanatory variables for directed generosity independent of the network dimension. Second, observable individual characteristics other than gender have no or negligible explanatory power in any specific network. Third, social distance is important only in the friendship network. Fourth, structural network variables play a significant role in determining giving behavior but the effects clearly differ across the different specific networks.

More specifically, in all investigated network dimensions female dictators give between 2.4 and 3.1 coins less to male recipients than male dictators do (cf. Male $\rightarrow$ Male). Moreover, male dictators give between 1.5 coins and 2.5 coins more to female recipients than female dictators give to male recipients (cf. Male $\rightarrow$ Female). The other variables controlling for individual characteristics are insignificant. The only exception is that in the social-public activities network poor dictators give marginally significantly less to rich recipients than rich dictators do (cf. NoCattle $\rightarrow$ Cattle). Overall, and in line with other studies (e.g., Camerer, 2003), the power of observable individual characteristics in explaining variations in generosity appears very limited. Indeed, a log-likelihood ratio test, comparing the model with only individual characteristics as explanatory variables with the reported full model shows that the fit of the latter is significantly better $(p<0.0001)$ for all investigated network dimensions. As in the network of general relations, general generosity (GiveStranger) is a strong albeit imperfect predictor of directed generosity in all specific networks. In each network dimension, an additional coin given to the stranger increases generosity towards the network recipient by a little less than half a coin. 
Table 6: Determinants of directed generosity in specific networks

\begin{tabular}{|c|c|c|c|c|c|c|c|c|}
\hline \multirow[b]{3}{*}{ Male $\rightarrow$ Female } & \multicolumn{8}{|c|}{ Dependent variable: Coins given to village recipient } \\
\hline & \multicolumn{2}{|c|}{ Friendship } & \multicolumn{2}{|c|}{ Support } & \multicolumn{2}{|c|}{ Social-public } & \multicolumn{2}{|c|}{ Economic } \\
\hline & $2.436^{* *}$ & $(1.179)$ & $2.372^{* * *}$ & $(0.794)$ & $2.488^{* * *}$ & $(0.861)$ & $1.512^{*}$ & $(0.862)$ \\
\hline Male $\rightarrow$ Male & $3.082^{* * *}$ & $(1.078)$ & $2.793^{* * *}$ & $(0.900)$ & $2.976^{* * *}$ & $(0.890)$ & $2.382^{* * *}$ & $(0.887)$ \\
\hline Female $\rightarrow$ Female & 0.708 & $(0.836)$ & $1.377^{* *}$ & $(0.651)$ & $1.329^{* *}$ & $(0.616)$ & $1.081^{*}$ & $(0.639)$ \\
\hline$A g e \_D$ & 0.059 & $(0.042)$ & 0.058 & $(0.044)$ & 0.041 & $(0.045)$ & 0.050 & $(0.044)$ \\
\hline$A g e \_\Delta$ & 0.008 & $(0.022)$ & 0.001 & $(0.024)$ & -0.004 & $(0.023)$ & 0.004 & $(0.022)$ \\
\hline Education_D & 0.038 & $(0.118)$ & 0.047 & $(0.143)$ & -0.027 & $(0.152)$ & -0.044 & $(0.133)$ \\
\hline Education_s & -0.021 & $(0.081)$ & -0.016 & $(0.079)$ & -0.004 & $(0.078)$ & 0.006 & $(0.076)$ \\
\hline Residence_D & -0.043 & $(0.031)$ & -0.037 & $(0.029)$ & -0.035 & $(0.031)$ & -0.036 & $(0.029)$ \\
\hline Residence_s & -0.012 & $(0.023)$ & -0.008 & $(0.022)$ & -0.004 & $(0.021)$ & -0.005 & $(0.023)$ \\
\hline Urban_D & 0.012 & $(0.132)$ & 0.151 & $(0.131)$ & 0.144 & $(0.143)$ & 0.130 & $(0.133)$ \\
\hline Urban_A & -0.079 & $(0.049)$ & -0.062 & $(0.045)$ & -0.078 & $(0.048)$ & -0.066 & $(0.047)$ \\
\hline Cattle $\rightarrow$ NoCattle & -0.331 & $(0.627)$ & -0.364 & $(0.650)$ & -0.361 & $(0.655)$ & -0.327 & $(0.641)$ \\
\hline NoCattle $\rightarrow$ Cattle & -0.917 & $(0.735)$ & -0.880 & $(0.716)$ & $-1.231^{*}$ & $(0.744)$ & -0.650 & $(0.760)$ \\
\hline NoCattle $\rightarrow$ NoCattle & -0.421 & $(0.857)$ & -0.546 & $(0.926)$ & -0.735 & $(0.970)$ & -0.304 & $(0.868)$ \\
\hline Land $\rightarrow$ NoLand & -0.076 & $(0.869)$ & -0.356 & $(0.876)$ & -0.404 & $(0.906)$ & -0.465 & $(0.928)$ \\
\hline NoLand $\rightarrow$ Land & -0.134 & $(0.946)$ & -0.128 & $(1.065)$ & -0.715 & $(1.010)$ & -0.684 & $(1.004)$ \\
\hline NoLand $\rightarrow$ NoLand & -0.468 & $(0.899)$ & 0.018 & $(1.131)$ & -0.659 & $(1.035)$ & -0.917 & $(0.992)$ \\
\hline Distant & $-1.304^{* *}$ & $(0.660)$ & -0.094 & $(0.962)$ & 0.630 & $(1.085)$ & 0.766 & $(0.862)$ \\
\hline Closure_D & $-0.011^{*}$ & $(0.006)$ & $0.294^{*}$ & $(0.168)$ & -0.020 & $(0.035)$ & $-0.152^{*}$ & $(0.080)$ \\
\hline Centrality_D & $0.791^{* *}$ & $(0.305)$ & -0.189 & $(0.129)$ & 0.290 & $(0.402)$ & $0.510^{* * *}$ & $(0.186)$ \\
\hline Closure_R & -0.004 & $(0.004)$ & 0.134 & $(0.117)$ & $0.023^{* *}$ & $(0.011)$ & $0.068^{* *}$ & $(0.034)$ \\
\hline Centrality_R $R$ & 0.050 & $(0.229)$ & -0.122 & $(0.094)$ & $-0.099^{* *}$ & $(0.047)$ & -0.157 & $(0.098)$ \\
\hline GiveStranger & $0.432^{* * *}$ & $(0.087)$ & $0.461^{* * *}$ & $(0.083)$ & $0.475^{* * *}$ & $(0.087)$ & $0.454^{* * *}$ & $(0.086)$ \\
\hline 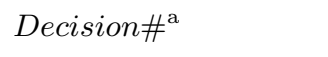 & \multicolumn{2}{|c|}{ n.s. } & \multicolumn{2}{|c|}{ n.s. } & \multicolumn{2}{|c|}{ n.s. } & \multicolumn{2}{|c|}{ n.s. } \\
\hline Constant & $5.562^{*}$ & $(2.929)$ & 3.384 & $(2.873)$ & 3.243 & $(3.670)$ & 3.271 & $(2.694)$ \\
\hline $\mathrm{R}^{2}$ & \multicolumn{2}{|c|}{0.4627} & \multicolumn{2}{|c|}{0.4474} & \multicolumn{2}{|c|}{0.4405} & \multicolumn{2}{|c|}{0.4915} \\
\hline F-statistics & \multicolumn{2}{|c|}{10.99} & \multicolumn{2}{|c|}{9.29} & \multicolumn{2}{|c|}{8.20} & \multicolumn{2}{|c|}{13.96} \\
\hline Prob $>F$ & \multicolumn{2}{|c|}{0.0000} & \multicolumn{2}{|c|}{0.0000} & \multicolumn{2}{|c|}{0.0000} & \multicolumn{2}{|c|}{0.0000} \\
\hline No. of obs. & \multicolumn{2}{|c|}{273} & \multicolumn{2}{|c|}{273} & \multicolumn{2}{|c|}{273} & \multicolumn{2}{|c|}{273} \\
\hline
\end{tabular}

Note: ${ }^{* * *},{ }^{* *},{ }^{*}$ indicate two-sided significance levels at 1,5 , and 10 percent, respectively; ${ }^{a}$... decision fixed effects are not significant (n.s.); robust standard errors (in parentheses) are obtained by means of two-way clustering at the level of dictators ( 57 clusters) and recipients (91 clusters).

In the friendship network social distance has a significant effect on directed generosity. Recipients who are not direct friends receive on average 1.3 coins less than direct friends. Surprisingly, closure and centrality show (marginally) significant signs opposite to those expected. Note, however, that the effect of $C l o s u r e \_D$, although statistically marginally significant, is extremely 
small. The significantly positive coefficient of betweenness centrality indicates that structurally more powerful dictators tend to be more generous. This is in contrast to Burt's conjecture that such positions are taken by people who pursue their self-interest. A plausible, albeit speculative, explanation for our result is that in small-scale societies power tends to be connected to clientelism, which can only be maintained if resources are also transferred to the dependent client (Wolf, 1977) 18 If our villagers bring this logic to the experiment, structurally powerful dictators may more strongly feel the responsibility to share with others than less powerful dictators do 19 The network variables relating to the recipient are insignificant.

In contrast to the friendship network, in the support network social distance does not play a significant role in explaining dictator giving. Instead the structural network measure $C l o s u r e \_D$ has a relatively large positive coefficient, which is also marginally significant. This result is consistent with Coleman's idea that network clustering fosters pro-social behavior. That this network variable has a positive influence in support networks, which are used to help each other, is also very intuitive. All other network variables are insignificant.

In the network created through social-public activities it is only the recipients' network measures that exhibit statistical significant effects on the dictators' giving decisions. The negative sign of $C e n t r a l i t y \_R$ indicates that receivers that are more central and, hence, more powerful in this network receive less than those who are less powerful. At the same time, the positive sign of Closure $R$ shows that those who are embedded in a denser cluster receive more from dictators than those only loosely embedded. Note, however, that the size of these effects is relatively small.

Finally, in the network of economic relations social distance does again not affect dictator giving. However, structural network variables related to the dictator and the recipient do have (marginally) significant effects on directed generosity. Dictators who are more strongly embedded in tight economic relationships tend to give less and those being more central give more to recipients. The former suggests that in dense economic clusters there is less room for generosity, probably because these economic relationships are based on contractual relations and not on generosity. As in the friendship network, the latter effect may be explained by power (i.e.,

\footnotetext{
${ }^{18}$ At first sight it may seem peculiar to talk about clientelism in friendship networks, but often the difference between friendship and clientelism is blurred. An interesting historical example for this is provided in Cole (2007) where it is shown how the friendship between Maffeo Barberini and Michelangelo Buonarroti the Younger slowly developed into a patron-client relation.

${ }^{19}$ Brañas-Garza et al. (2010) also find a positive effect of betweenness centrality on dictator giving. These authors' interpret betweenness centrality as a measure of social integration and conclude that social integration fosters generosity. We do not follow this interpretation, because the sociological network literature does not suggest that betweenness centrality captures social integration. According to Wasserman and Faust (1994, p. 189) it rather measures the "'interpersonal influence' on others (...) [and] the strategic importance of locations on geodesics."
} 
centrality in the network) being closely related to clientelism. The regression results also show that the stronger a recipient is embedded in tight economic relations the more she receives from dictators. A possible reason for this effect is that having many tight business ties signals many alternative trading opportunities.

In summary, the results of this section show that, except for gender, observable characteristics on the individual as well as dyad level do not have explanatory power for dictator giving to recipients, neither in the network of general relations nor in any of the specific networks. Regarding gender it is surprisingly the female dictators who give less than male dictators. This strongly contrasts with lab dictator game experiments where either no gender effects are found or where it is observed that female dictators are more generous than male dictators (cf. Croson and Gneezv), 2009, for a recent survey). A possible reconciliation for this contrasting results is that experiments where a positive female gender effect was found were all conducted in rich countries, mainly using student subjects. Young female students in these countries are, however, hardly comparable to relatively poor adult female household heads in rural areas of poor countries in the South. Indeed, there is some evidence from developing countries that income in female hands substantially increases children's health and also increases food shares (Thomas, 1990; Hoddinott and Haddad, 1995). Therefore, our female dictators may rather have kept the money for household spending purposes than to give it away.

In contrast to the observable individual characteristics general generosity and the network variables do explain variation in dictator giving. Importantly, while general generosity exhibits a significant effect independent of the investigated network, the effect of social distance and the structural network variables are not constant across networks of different dimensions. In line with studies examining only friendship networks among students and pupils we find that social distance matters in friendship networks. Importantly, however, we do not find such an effect for any other network dimension, implying that social distance may matter only in friendship networks. Furthermore, structural network variables regarding the dictator and the recipient are clearly related to dictator giving. However, the actual effects and even the signs of these variables change across the different specific networks. Hence, for explaining directed generosity it clearly matters what network one is looking at.

\subsection{Determinants of network formation}

In the previous section we showed that observable individual characteristics cease to explain directed generosity, once we control for general generosity, social distance and structural network variables. However, there may exist an indirect effect of individual characteristics on dictator giving via network formation. For instance, Glaeser et al. (2002) have shown that such charac- 
teristics can explain variations in individuals' social capital. Since social and economic links can also be considered as a form of social capital (cf. Lin, 1999) we expect to find an effect of these variables on the likelihood that ties between nodes exist.

To investigate network formation we explore determinants of linking choices in the following way. For each network dimension, except neighbor relations, we examine a regression model that estimates the probability $P_{i j}$ of an undirected link between each pair of nodes $i j$ as a function of observable characteristics at the individual node level and the dyad level. Let $\boldsymbol{Z}_{i}$ and $\boldsymbol{Z}_{j}$ be vectors of specific individual characteristics (age, wealth, etc.) of nodes $i$ and $j$. For each dyad $i j$ we take the sum, $\boldsymbol{Z}_{i}+\boldsymbol{Z}_{j}$, as well as the absolute value of the difference, $\left|\boldsymbol{Z}_{i}-\boldsymbol{Z}_{j}\right|$, as explanatory variables for link formation. The former, denoted by $Z_{-} \Sigma$, measures a possible level effect of characteristics whereas the latter, denoted be $Z \_\Delta$, measures the effect of a difference in attributes. For $Z \_\Delta$ we expect to find significantly negative effects because of a human tendency to team up with similar others, a phenomenon documented extensively in the sociological literature (see, e.g., McPherson et al., 2001, for a survey). In addition, let $\boldsymbol{W}_{i j}$ be the vector of other characteristics that may relate nodes $i$ and $j$, such as being neighbors, having the same or different gender, etc.

Formally, we estimate the following logistic regression model 20

$$
\operatorname{logit}\left(P_{i j}\right)=\ln \left(\frac{P_{i j}}{1-P_{i j}}\right)=\alpha+\beta_{1}\left|\boldsymbol{Z}_{i}-\boldsymbol{Z}_{j}\right|+\beta_{2}\left(\boldsymbol{Z}_{i}+\boldsymbol{Z}_{j}\right)+\gamma \boldsymbol{W}_{i j}
$$

As explanatory variables we include the same set of observable characteristics as in the models of the previous section: gender, age, years of education, years of residence in the village, frequency of contacts to the urban center, possession of cattle and land. In addition, we also control for being linked by neighborhood at various distances. To study gender, wealth and neighborhood effects we take male-male dyads, dyads where both nodes possess cattle and land, and direct neighbors, respectively, as benchmarks. In the regressions, we consider all potential links between the 123 household heads, save intra-household links.

Table 7 shows the results for friendship and support relations, for relations through social public activities, and for economic relations. The overall picture is that some observable characteristics are indeed important for link formation throughout all network dimensions, while others play a role only for some networks, and a third set turns out to be completely unrelated with link formation in all dimensions.

For all network dimensions, except economic relations, the likelihood of a link between a female and a male node (Female $\leftrightarrow$ Male) is highly significantly smaller than between two male

\footnotetext{
${ }^{20}$ Dyadic observations involving the same node can not be considered independent, that is $E\left[e_{i j}, e_{i k}\right] \neq 0$ for all $k$, and $E\left[e_{i j}, e_{k j}\right] \neq 0$ for all $k$. To correct standard errors for these dependencies we apply clustering on both dimensions separately (Cameron et al., 2010; Fafchamps and Gubert, 2007).
} 
Table 7: Determinants of network formation

\begin{tabular}{|c|c|c|c|c|c|c|c|c|}
\hline \multirow[b]{3}{*}{ Female $\leftrightarrow$ Male } & \multicolumn{8}{|c|}{ Dependent variable: likelihood of link between any two nodes $i j$} \\
\hline & \multicolumn{2}{|c|}{ Friendship } & \multicolumn{2}{|c|}{ Support } & \multicolumn{2}{|c|}{ Social-public } & \multicolumn{2}{|c|}{ Economic } \\
\hline & $-1.354^{* * *}$ & $(0.154)$ & $-0.657^{* * *}$ & $(0.248)$ & $-0.729^{* * *}$ & $(0.235)$ & $-0.486^{*}$ & $(0.250)$ \\
\hline Female $\leftrightarrow$ Female & $-1.495^{* * *}$ & $(0.251)$ & -0.414 & $(0.403)$ & $-0.661^{*}$ & $(0.385)^{*}$ & -0.150 & $(0.594)$ \\
\hline $\mathrm{Age}_{-} \Sigma$ & 0.004 & $(0.006)$ & 0.001 & $(0.006)$ & 0.014 & $(0.009)$ & 0.011 & $(0.010)$ \\
\hline Age_s & $-0.009^{*}$ & $(0.005)$ & $-0.025^{* *}$ & $(0.012)$ & $-0.046^{* * *}$ & $(0.008)$ & -0.011 & $(0.014)$ \\
\hline Education_s & $0.047^{* *}$ & $(0.020)$ & -0.018 & $(0.032)$ & $0.070^{*}$ & $(0.041)$ & 0.008 & $(0.027)$ \\
\hline Education_s & -0.006 & $(0.017)$ & 0.004 & $(0.031)$ & $0.047^{*}$ & $(0.027)$ & 0.013 & $(0.028)$ \\
\hline Residence_$\Sigma_{-}$ & 0.006 & $(0.005)$ & -0.010 & $(0.010)$ & -0.005 & $(0.006)$ & -0.012 & $(0.011)$ \\
\hline Residence_s & -0.008 & $(0.005)$ & -0.005 & $(0.013)$ & -0.001 & $(0.009)$ & 0.009 & $(0.011)$ \\
\hline Urban_ $\_$ & 0.040 & $(0.026)$ & -0.010 & $(0.059)$ & 0.043 & $(0.037)$ & $0.140^{* * *}$ & $(0.041)$ \\
\hline Urban_A & $-0.048^{* *}$ & $(0.024)$ & -0.005 & $(0.060)$ & $-0.079^{* *}$ & $(0.037)$ & $-0.104^{* *}$ & $(0.044)$ \\
\hline Cattle $\leftrightarrow$ NoCattle & $-0.368^{* *}$ & $(0.147)$ & -0.199 & $(0.422)$ & -0.029 & $(0.336)$ & $-0.671^{* *}$ & $(0.274)$ \\
\hline NoCattle $\leftrightarrow$ NoCattle & $-0.570^{* *}$ & $(0.268)$ & $-1.068^{*}$ & $(0.578)$ & -0.321 & $(0.511)$ & $-2.007^{* * *}$ & $(0.662)$ \\
\hline Land $\leftrightarrow$ NoLand & 0.104 & $(0.214)$ & 0.013 & $(0.532)$ & -0.338 & $(0.427)$ & $1.031^{*}$ & $(0.552)$ \\
\hline NoLand $\leftrightarrow$ NoLand & 0.322 & $(0.328)$ & 0.001 & $(0.643)$ & -0.346 & $(0.599)$ & $1.627^{*}$ & $(0.840)$ \\
\hline Neighbor_Dist2 & $-0.982^{* * *}$ & $(0.176)$ & $-1.523^{* * *}$ & $(0.292)$ & 0.025 & $(0.227)$ & 0.010 & $(0.338)$ \\
\hline Neighbor_Dist3 & $-1.053^{* * *}$ & $(0.185)$ & $-1.708^{* * *}$ & $(0.302)$ & 0.015 & $(0.310)$ & -0.186 & $(0.327)$ \\
\hline Neighbor_Dist4 & $-1.294^{* * *}$ & $(0.227)$ & $-1.794^{* * *}$ & $(0.420) 2$ & -0.220 & $(0.389)$ & -0.437 & $(0.326)$ \\
\hline Neighbor_Dist $>4$ & $-1.942^{* * *}$ & $(0.315)$ & $-2.973^{* * *}$ & $(0.536)$ & -0.366 & $(0.567)$ & -0.365 & $(0.441)$ \\
\hline Constant & -0.089 & $(0.781)$ & -0.038 & $(1.080)$ & $-3.021^{* *}$ & $(1.238)$ & $-3.716^{* * *}$ & $(1.258)$ \\
\hline $\operatorname{LR} \chi^{2}$ & \multicolumn{2}{|c|}{482.95} & \multicolumn{2}{|c|}{98.17} & \multicolumn{2}{|c|}{118.71} & \multicolumn{2}{|c|}{151.33} \\
\hline Prob $>\chi^{2}$ & \multicolumn{2}{|c|}{0.0000} & \multicolumn{2}{|c|}{0.0000} & \multicolumn{2}{|c|}{0.0000} & \multicolumn{2}{|c|}{0.0000} \\
\hline No. of obs. & \multicolumn{2}{|c|}{4809} & \multicolumn{2}{|c|}{4809} & \multicolumn{2}{|c|}{4809} & \multicolumn{2}{|c|}{4809} \\
\hline
\end{tabular}

Note: ${ }^{* * *},{ }^{* *},{ }^{*}$ indicate two-sided significance levels at 1,5 , and 10 percent, respectively; $x \leftrightarrow y$ assumes value 1 if in a dyad $i j$ node $i$ has characteristic $x(y)$ and $j$ has characteristic $y(x), 0$ otherwise. Robust standard errors (in parentheses) are obtained by means of two-way clustering at the dyad level (97 clusters).

nodes. For the economic network this effect is only marginally significant. In the friendship network also ties between two women (Female $\leftrightarrow$ Female) are significantly less likely than between two men. For social-public relations this effect is still marginally significant, but insignificant for support and economic relations. Hence, when it comes to link formation gender effects are most pronounced in the social sphere (friendship relations) but basically non-existent in the business sphere (economic relations).

Age does not have a level effect, but nodes closer in age are significantly more likely to have support and social-public links. The latter effect is also marginally significant for friendship ties but insignificant for economic relations. This suggests that age homophily is relevant for the more social relations but not for the business-like network. Education, on the other hand, exerts a significant level effect in the friendship network and a marginally significant effect in the network of social-public relations. This indicates that better educated people have more friendship ties and meet more often at social and public events than lower educated ones. The social-public 
network is the only network where differences in education exert a (marginally) significant effect on tie formation. The positive sign probably indicates that such public events play an integrative role as it makes villagers with different socio-economic characteristics meet each other.

The frequency of contact with the nearest urban center exerts a strong level effect on the formation of the economic network in the village. People who visit the urban center more often are also more likely to have business-like relations. Intuitively this makes sense because many visits to the urban center have a business background. Regarding the frequency of visits to the urban center, there is also an interesting and strong homophily effect for economic, friendship and social-public relations. The likelihood of having a tie in these networks gets significantly larger the smaller the differences in frequencies of visits of the urban center becomes.

The variables approximating wealth are important for forming friendship ties and economic relations. Relative to wealthy dyads, especially those owning cattle, the chance of a friendship or economic link is significantly smaller for dyads consisting of a poor and wealthy node. Moreover, a dyad of two poor nodes is also significantly less likely to have friendship and economic links than wealthy dyads. This clearly indicates that being poor is strongly associated with exclusion from social and economic networks.

Finally, we observe that the likelihood of a friendship and a support link significantly decreases with the distance along the neighbor dimension. This indicates that friendship and support relations are more likely among close neighbors than among villagers at larger distances.

In summary, we find that many observable characteristics have a significant and intuitive effect on network formation. Yet, the set of variables with explanatory power only partly overlaps for the specific networks. Among the different network dimensions the formation of economic relations appears most 'rational' in the sense that mainly economically relevant characteristics exert a significant effect on link formation. In contrast, tie formation in the more social dimensions, especially friendship and support ties, are more strongly influenced by non-economic variables like age, education, gender and being neighbors. With respect to generosity, the results in this section strongly suggest that some observable individual characteristics, while not having a direct effect as shown in Section 3.2. may still exert an indirect influence through their effect on network formation.

\section{Summary and Conclusion}

In this paper we report on the individual and network related determinants of directed generosity in the field. For a rural village in Nicaragua we elicited observable characteristics of villagers as well as complete networks of different dimensions among (almost) all household heads. This 
provided us not only with large variations in socio-economic characteristics but also with widely varying structural network variables and network positions of villagers. To explore the determinants of directed generosity we implemented a series of dictator games played by household heads with village recipients as well as with a stranger, and relate it to observable characteristics and network variables. In addition, we explore the effect of individual characteristics on network formation for different specific networks.

Existing studies investigating the influence of network variables on generosity relied on the special subject pool of relatively wealthy students in the Northern hemisphere. Moreover, these studies confined their network research to friendship ties. In our research, besides friendship networks we also elicited other specific networks people are simultaneously embedded in, such as networks through support relations, relations via social-public activities and economic relations. As a consequence, we obtained a very rich data set that allows us to check the robustness of results reported in the aforementioned studies and, importantly, whether these results extend to other network dimensions.

An important first result is that networks of different dimensions exhibit only limited overlap and differ strongly in structural network variables like density, clustering, and centrality. For instance, friendship networks are very dense and little centralized whereas the network of economic ties is relatively loose and much more centralized.

Regarding the determinants of directed generosity we find that observable individual characteristics have hardly explanatory power for giving in the experimental dictator games. In our study, the only characteristic that clearly exhibits influence is gender. We find that female dictators give significantly less than male dictators, especially when the recipient is male. In view of the literature on gender differences and social preferences, that usually find the opposite (cf. Croson and Gneezv, 2009), this is surprising. However, recent work shows that cultural differences can have a strong effect on social behavior of the genders (cf. Gneezv et al., 2009). Therefore, a reasonable explanation can be found in our very different subject pool. The social position and responsibilities of adult women in a rural village in Nicaragua are very different from those of young female students in wealthy countries. In particular, these women are responsible for keeping up the resources in the family, which may rather make them keep the money than giving it to male recipients.

Regarding network variables we find that in friendship networks the social geodesic distance is an important indicator for giving behavior. This is in line with the findings obtained with student subjects (cf. Leider et al., 2009; Goeree et al., 2010). We consider this an important observation for network and experimental research because it indicates that social distance is an important indicator for giving behavior across very different cultures and social groups. However, 
in stark contrast to friendship networks, social distance has no explanatory power at all in the other investigated specific networks, suggesting that friendship ties are special in this respect.

Our data analyses also show that structural network variables affect giving behavior in all specific networks. Yet, these effects are not constant across the network dimensions. Betweenness centrality of the dictator exhibits a positive influence on directed generosity in friendship and economic ties, but is insignificant in the other networks. The positive influence in the mentioned networks runs counter to Burt's (1992) idea that those who are central in the betweenness sense are better equipped to pursue their self interest. We attribute this result to the fact that in small-scale societies and other relatively small groups power (i.e., centrality) is often connected to clientelism, which needs occasionally resources to be transferred to the dependent. We also find that dictators who have a locally dense network tend to be more generous in support networks, which is in line with Coleman's (1990) hypothesis that higher clustering facilitates pro-social behavior. Interestingly, in the economic network this effect is reversed indicating that closure in business-like relations has a very different meaning than closure in ties of support and mutual help. One general lesson that can be drawn next to the specific results is that for the explanation of giving behavior network dimension clearly matters.

In our view this has at least two important implications. First, for empirical and theoretical network research it implies that one has to be careful in drawing general conclusions regarding the influence of network positions and structures on behavior from observations and results gained for networks of a particular dimension. For theory it also means that abstracting completely from the network content, when analyzing network formation and behavior on networks, may lead to inaccurate predictions and misleading normative prescriptions. Second, also for policy design it may matter what network dimensions and structures influence directed generosity. For instance, a growing number of policymakers and aid donors make use of local communities and networks to distribute development aid. The World Bank, for example, has increased its portfolio of projects that follow such an approach substantially over the last decade (cf. Mansuri and Rao, 2004). Based on our results, individuals in highly clustered sub-networks of support relations or individuals who are central in friendship relations may be more inclined to share aid resources with other village members. At the same time, social distance in friendship relations may be an important factor of exclusion. The latter together with the observed lower likelihood of the poor of having friendship relations identifies an important policy challenge in this area.

Another interesting aspect is that other studies do not find any effects of structural network variables on giving behavior. For instance, Goeree et al. (2010, p. 193) conclude that their "three social network structure measures are not statistically significant and represent very weak effects." In contrast to these findings, we see that structural network variables do matter for 
giving behavior. This is likely the result of the substantial difference in variation of these variables and related statistical power between our dataset and data used in previous studies. Whereas these studies relied on relatively homogeneous student groups, we had access to networks of a long-grown social unit which - as shown in Section 2- consists of very heterogeneous members.

Although, we do not find direct effects of observable characteristics except gender, we have strong indications that such characteristics play an important indirect role via the route of network formation. As is the case for giving behavior, also in network formation these effects differ across the specific networks. Hence, individual characteristics are affecting generosity because they determine to whom one is connected and what position one takes in the specific network.

We have investigated the influence of networks on social decisions in a rural village in a poor country in the South. However, small-scale networks are ubiquitous in social and economic life. More often than not, decisions are made by agents embedded in networks of different kinds. For instance, employees in small firms form small-scale networks, as work units in larger firms, law offices, and units in financial institutions do. The same holds for research groups and departments at universities. In all these networks economically and socially linked individuals make decisions affecting important outcomes. Our study has shown that these decisions are likely influenced by the network structure and position of individuals in the network and that these influences differ across different network dimensions. Whether these results carry over to other networks and other decision situations has to be answered by future research. 


\section{References}

Andreoni, J. (2006). Philanthropy. In Kolm, S.-C. and Ythier, J. M., editors, Handbook of Giving, Reciprocity and Altruism, pages 1201-1269. North Holland, Amsterdam.

Andreoni, J. (2008). Charitable giving. In Durlauf, S. N. and Blume, L. E., editors, The New Palgrave Dictionary of Economics. Second Edition. Palgrave Macmillan. The New Palgrave Dictionary of Economics Online. doi:10.1057/9780230226203.0221.

Andreoni, J. and Vesterlund, L. (2001). Which is the fair sex? Gender differences in altruism. Quarterly Journal of Economics, 116(1):293-312.

Bandiera, O., Barankay, I., and Rasul, I. (2009). Social connections and incentives in the workplace: Evidence from personnel data. Econometrica, 77(4):1047-1094.

Bardsley, N. (2008). Dictator game giving: Altruism or artefact? Experimental Economics, $11(2): 122-133$.

Bertrand, M., Luttmer, E. F. P., and Mullainathan, S. (2000). Network effects and welfare culture. Quarterly Journal of Economics, 115(3):1019-1055.

Bohnet, I. and Frey, B. S. (1999). The sound of silence in prisoner's dilemma and dictator games. Journal of Economic Behavior and Organization.

Brañas-Garza, P. (2006). Poverty in dictator games: Awakening solidarity. Journal of Economic Behavior and Organization, 60(3):306-320.

Brañas-Garza, P., Cobo-Reyes, R., Espinosa, M. P., Jiménez, N., Kovárík, J., and Ponti, G. (2010). Altruism and social integration. Games and Economic Behavior, 69(2):249-257.

Burt, R. S. (1992). Structural holes: The social structure of competition. Harvard University Press, Cambridge, MA, and London, England.

Burt, R. S. (2005). Brokerage and closure: An introduction to social capital. Oxford University Press, Oxford, U.K.

Camerer, C. (2003). Behavioral game theory: experiments in strategic interaction. Princeton University Press, New York and Princeton.

Cameron, A. C., Gelbach, J. B., and Miller, D. L. (2010). Robust inference with multi-way clustering. Journal of Business and Economic Statistics. forthcoming. 
Cappelen, A. W., Moene, K. O., Sørensen, E. Ø., and Tungodden, B. (2008). Rich meet poor An international fairness experiment. Discussion Paper TI 2008-098/3, Tinbergen Institute.

Cardenas, J.-C., Stranlund, J. K., and Willis, C. (2000). Local environmental control and institutional crowding-out. World Development, 28(10):1719-1733.

Carpenter, J., Connolly, C., and Myers, C. K. (2008). Altruistic behavior in a representative dictator experiment. Experimental Economics, 11(3):282-298.

Casella, A. and Rauch, J. E. (2002). Anonymous market and group ties in international trade. Journal of International Economics, 58(1):19-47.

Chen, Y. and Li, S. X. (2009). Group identity and social preferences. American Economic Review, 99(1):431-457.

Cole, J. (2007). Cultural clientelism and brokerage networks in early modern Florence and Rome: New correspondence between the Barberini and Michelangelo Buonarroti the Younger. Renaissance Quarterly, 60(3):729-788.

Coleman, J. S. (1988). Social capital in the creation of human capital. American Journal of Sociology, 94:S95-S120.

Coleman, J. S. (1990). Foundations of social theory. Harvard University Press, Harvard, MA.

Croson, R. and Gneezy, U. (2009). Gender differences in preferences. Journal of Economic Literature, $47(2): 448-474$.

De Weerdt, J. and Dercon, S. (2006). Risk-sharing networks and insurance against illness. Journal of Development Economics, 81(2):337-356.

Eckel, C. C. and Grossman, P. J. (1996). Altruism in anonymous dictator games. Games and Economic Behavior, 16(2):181-191.

Eckel, C. C. and Grossman, P. J. (1998). Aew women less selfish than men? evidence from dictator experiments. Economic Journal, 108(448):726-735.

Efferson, C., Lalive, R., and Fehr, E. (2008). The coevolution of cultural groups and ingroup favoritism. Science, 321(5897):1844-1849.

Egas, M. and Riedl, A. (2008). The economics of altruistic punishment and the maintenance of cooperation. Proceedings of the Royal Society - B, 275(1637):871-878. 
Fafchamps, M. and Gubert, F. (2007). The formation of risk sharing networks. Journal of Development Economics, 83(2):326-350.

Fafchamps, M. and Lund, S. (2003). Risk-sharing networks in rural Philippines. Journal of Development Economics, 71(2):261-287.

Fisman, R., Kariv, S., and Markovits, D. (2007). Individual preferences for giving. American Economic Review, 97(5):1858-1876.

Freeman, L. C. (1977). A set of measures of centrality based on betweenness. Sociometry, $40(1): 35-41$.

Freeman, L. C. (1978-1979). Centrality in social networks conceptual clarification. Social Networks, 1(3):215-239.

Glaeser, E. L., Laibson, D. I., and Sacerdote, B. (2002). An economic approach to social capital. The Economic Journal, 112(483):437-458.

Gneezy, U., Leonard, K. L., and List, J. A. (2009). Gender differences in competition: Evidence from a matrilineal and a patriarchal society. Econometrica, 77(5):1637-1664.

Goeree, J. K., McConnell, M. A., Mitchell, T., Tromp, T., and Yariv, L. (2010). The 1/d law of giving. American Economic Journal: Microeconomics, 1(1):183-203.

Granovetter, M. (1973). The strength of weak ties. American Journal of Sociology, 78(6):13601380.

Granovetter, M. ([1974]1995). Getting a job: A study of Contacts and Careers. The University of Chicago Press, second edition.

Henrich, J., Boyd, R., Bowles, S., Camerer, C., Fehr, E., and Gintis, H., editors (2004). Foundations of Human Sociality: Economic Experiments and Ethnographic Evidence from Fifteen Small-Scale Societies. Oxford University Press, Oxford U.K.

Henrich, J., Boyd, R., Bowles, S., Camerer, C., Fehr, E., Gintis, H., McElreath, R., Alvard, M., Barr, A., Ensminger, J., Henrich, N. S., Hill, K., Gil-White, F., Gurven, M., Marlowe, F. W., Patton, J. Q., and Tracer, D. (2005). "Economic man" in cross-cultural perspective: Behavioral experiments in 15 small-scale societies. Behavioral and Brain Sciences, 28:795-815.

Henrich, J., Heine, S. J., and Norenzayan, A. (2010). The weirdest people in the world? Behavioral and Brain Sciences, 33:61-135. 
Hoddinott, J. and Haddad, L. (1995). Does female income share influence household expenditures? Evidence from Côte d'Ivoire. Oxford Bulletin of Economics and Statistics, 57(1):77-96.

Ioannides, Y. M. and Loury, L. D. (2004). Job information networks, neighborhood effects, and inequality. The Journal of Economic Literature, 42(4):1052-1093.

Jackson, M. O., Rodriguez-Barraquer, T., and Tan, X. (2010). Social capital and social quilts: Network patterns of favor exchange. mimeo.

Karlan, D. S. (2007). Social connections and group banking. The Economic Journal, 117(517):F52-F84.

Konow, J., Saijo, T., and Akai, K. (2008). Morals and mores? Experimental evidence on equity and equality from the US and Japan. Technical report, Imstitute of Social and Economic Research, Osaka University.

Leider, S., Möbius, M. M., Rosenblat, T., and Do, Q.-A. (2009). Directed altruism and enforced reciprocity in social networks. Quarterly Journal of Economics, 124(4):1815-1851.

Lin, N. (1999). Building a network theory of social capital. Connections, 22(1):28-51.

List, J. A. (2004). Young, selfish and male: Field evidence of social preferences. The Economic Journal, 114(292):121-149.

List, J. A. (2007). On the interpretation of giving in dictator games. Journal of Political Economy, 115(3):482-493.

Mansuri, G. and Rao, V. (2004). Community-based and -driven development: A critical review. The World Bank Observer, 19(1):1-39.

McMillan, J. and Woodruff, C. (1999). Interfirm relationships and informal credit in Vietnam. Quarterly Journal of Economics, 114(4):1285-1320.

McPherson, M., Smith-Lovin, L., and Cook, J. M. (2001). Birds of a feather: Homophily in social networks. Annual Review of Sociology, 27:415-444.

Montgomery, J. D. (1991). Social networks and labor-market outcomes: Toward an economic analysis. American Economic Review, 81(5):1408-1418.

Munshi, K. (2003). Networks in the modern economy: Mexican migrants in the U.S. labor market. Quarterly Journal of Economics, 118(2):549-599. 
Newman, M. E. J. (2003). The structure and function of complex networks. SIAM Review, 45:167-256.

Podolny, J. M. and Baron, J. N. (1997). Resources and relationships: Social networks and mobility in the workplace. American Sociological Review, 62(5):673-693.

Rees, A. (1966). Information networks in labor economics. American Economic Review, $56(1 / 2): 559-566$.

Thomas, D. (1990). Intra-household resource allocation: An inferential approach. Journal of Human Resources, 25(4):635-664.

van Dijk, F., Sonnemans, J., and van Winden, F. (2002). Social ties in a public good experiment. Journal of Public Economics, 85(2):275-299.

Wasserman, S. and Faust, K. (1994). Social Network Analysis: Methods and Applications, volume 8 of Structural Analysis in the Social Sciences. Cambridge University Press, Cambridge U.K.

Wolf, E. R. (1977). Kinship, friendship, and patron-client relations in complex societies. In Schmidt, S. W., editor, Friends, Followers and Factions: A Reader in Political Clientelism. University of California Press, Berkeley. 


\section{Appendix}

\section{A Village Background, Design Details and Experimental In- structions}

\section{A.1 Brief village background}

The investigated village is located in a rural area in the Northern part of the Pacific region of Nicaragua, close to the border with Honduras. The difficult agro-ecological conditions (dry season, irregular rainfall, low fertility of soils, etc.) make agricultural activities not very profitable. Cattle breeding is one of the most lucrative economic activities in the region because it is both an income source and an important savings instrument that enables local people to bridge the long and harsh dry season. The possession of cattle is therefore an important indicator of wealth.

\section{A.2 Procedures for household and network survey and the experiment}

We conducted the household survey in a standard manner, by visiting the households in the village and interviewing the household head(s). The following criteria were taken into account when selecting the experimenter-assistants. We selected assistants with research experience in rural areas. They all were employees of the research and development institute Nitlapán of the Central American University, with which we have a close cooperation. This enabled us to screen the researchers with regard to their dedication, their capacity to work in a systematic way, their trustworthiness and their capacity to radiate trust towards other people (such as the participants in our experiment).

The training of the assistants was crucial as none of them had any prior experience with conducting experiments. To make them familiar with experimental methods we let them participate in an ultimatum game. After explaining the instructions of our dictator experiment we let them play a role-playing game whereby each assistant acted in the role of dictator and experimenter. The other assistants observed each role-playing session and were allowed to comment afterwards. The aim of this was to come to a common understanding of the experimental procedures. Thereafter, we conducted two pilot studies. After each pilot study the assistants informed the other assistants about their experience, who could then give their comments or suggestions. One session was recorded on video (download and play video). The video was shown to the team and allowed us to clarify any remaining open issues.

To build trust with the locals in the village, we first conducted the household survey followed by the network survey. Our work was supported by the local well-respected community leader who before the start of our study presented our team to each household and asked people to cooperate. He also explained the village members that our study was not related with politics, religion or aid projects in any way, and that we would treat the obtained information in a confidential way.

For the household survey we targeted for all households. If a household head was not present, we interviewed the other household head. For the social network survey we interviewed both household heads (in case of a two-headed household) of as many households as possible. In case one household head was absent 
we asked whether he or she would be available within the time span of our field planning and returned later to also interview this person. In this way we obtain almost complete coverage of the village. For a high coverage rate a good timing of our study was also important. When we were conducting our study most seasonal migrants had already returned to the village and economic activity was still low as villagers were awaiting the start of the economically more active rain season.

For the social network survey, we used small cards, each representing a household in the village. On each card we put the names of the household heads. In case of two-headed households the names of both, husband and wife, were put on the card. We asked for each of these cards whether the interviewed person knew the household and whether he or she had a social relation of any kind with any of the household heads. If a social relation was identified we asked for details on the type of social relation. Before the start of this exercise we had explained the different types of relations (land rental, labor transaction, religion, politics, school, sports, cooperatives, projects, neighbors, family, friendship, support, commercial relation), so that each participant would consider the same types of social relations 21

After finishing the household survey and the network survey (which took four days all together), we immediately organized the experiment on the fifth day. By conducting the experiment in only one day we minimized contagion and information spill-overs. To explain the instructions, fixed scripts were used (see Appendix A.3), which were memorized by the assistants. We decided not to read them aloud from paper as this could make participants loosing interest. After explaining the instructions to the participant, some pre-play questions were asked to test whether the participant had understood the instructions. We prohibited our assistants to invent other examples than the ones included in the instructions, to make references to the daily life of the participants when explaining the instructions, to make jokes (e.g., about the money the dictator could keep for himself) or to remove the tap of one of the small boxes once they were sealed.

We tried to conduct the experiment with as many households as possible, but with only one person per household. Letting two household heads sequentially participate in the experiment would have put the door open for contagion. If the selected household head was not present (and also could not be expected to be present on the same day of our experiment) we selected the other household head, in case of a twoheaded household. The assistants also asked some post-experimental questions and made a subjective evaluation about the participant's dedication, trust and understanding of the experiment. For this, the assistants had to answer the following questions for each participant:

1. How dedicated was the participant within the experiment?

1. Well dedicated 2. Neutral 3. Aversive; distrust towards the aim of the experiment

2. Did the participant understand the instructions?

1. No problems 2. Some questions for clarification 3. I have serious doubts about whether he/she completely understood them.

\footnotetext{
${ }^{21}$ For the analysis we summarized the elicited categories in the following way: the dimension economic relation consists of relations pertaining to land rental, labor transaction, and commercial relations; social public activities contain religion, politics, school, sports, cooperatives, and projects; the remaining categories neighbors, family, friendship, and support are not merged.
} 
3. Was he/she reluctant to take a decision?

1. Yes 2. No

4. On average, how much time did he/she take to make a decision?

1. Instantly 2. More than a minute 3. More than three minutes

5. Other personal observations:

\section{A.3 Experimental Instructions}

The experimental instructions are originally in Spanish; text between [] are instructions for the experimenter assistant. A short movie - recorded during a pilot experiment - showing a sequence with the instructions and decisions made can be found at: download and play video

We now ask you to participate in an experiment in which you can earn money. The amount of money you earn is yours, whatever the amount is.

Soon I will give you 20 coins of 1 Córdoba and you will be free to divide this amount between yourself and another person. For this, we use this small black box [show the box]. In this box, you will find 20 coins of 1 Córdoba [open the box and show the 20 coins]. You are allowed to take as many coins as you wish. The coins you leave in the box will be given to another person. In particular, we ask you to do the following:

1. Take the number of coins you want to keep out of the box and leave in the box the coins you want to give to the other person.

2. Refill the box with these small rings [show metal rings] and put the lid on the box. In this way, I will not be able to see how many coins you will have left in the box, nor can I get an idea about it through the weight of the box. The weight of the box will always be the same whatever the amount of coins you leave in the box.

Thereafter, we put a sticker on the box with the name of the person who will get the coins and we put some tape on it to seal the box. I will give the box to my supervisor, who waits at the automobile and who will bring the coins to the other person. Note that you will know the identity of the other person, whereas that other person will NOT know your identity.

I will now give you some arbitrary examples for further clarification. [Take the coins of one of the boxes and use them for the examples].

1. You have here 20 coins of 1 Córdoba. Imagine that you decide to take 2 coins out of the box. How many coins will the other person receive? (20 minus 2 equals 18)

2. I will give you another example. Imagine that you decide to take 10 coins out of the box. How many coins will the other person receive? (20 minus 10 equals 10)

3. I will give you a final example. Imagine that you decide to take 20 coins out of the box. How many coins will the other person receive? (20 minus 20 equals 0 ).

We will repeat this experiment 6 times. Each time, you will be able to take coins and leave coins for the other person, who will each time be a different one. Thus, I will give you 6 boxes of 20 coins to divide 
between yourself and another person. Each time, this person will be a different one. The first time you will divide the 20 coins with someone from another village in this region. You will not know this person. The other 5 times you will divide 20 coins with someone from your community. Once again, note that these other person will NOT know your identity.

To select the five persons of your community, I will ask you to take small cards from this bag. Each card has a different number, and each number corresponds to a different person in the community. After having taken a number, I will look up this number on a list and tell you the name of that person. Thereafter, I will give you a box with coins, so that you can decide on the number of coins you keep and how many you give to the other person. When taking this decision, I will give you privacy. You can go inside your house, [if this is not possible, say: I will turn my back so that I will be unable to know your decision; give me a signal when you are ready]. Please do not tell me the decision you will make or you have taken.

After having taken your decision and having closed the box we will seal the box, and you are not allowed anymore to change your decision. Thereafter, we will draw another number from the bag and I will ask you to take the next decision. Do you have any questions at the moment? 


\section{B Supplementary Network Data}

\section{B.1 Reciprocation Rates}

In our analysis we followed recent studies (cf. Leider et al., 2009; Jackson et al., 2010) and used so-called OR-networks. The alternative would have been to use AND-networks where links are taken to be valid only if both sides of a dyad mention the relation. There are at least three arguments in favor of the use of OR-networks, all related to the danger to miss out actually existing links when using AND-networks. First, generally while it is likely that a person forgets to mention a link, it seems much less likely that he or she 'invents' a link. Second, those who have many links are more likely to forget to mention a link than those who have only a few links. Third, people may put different emphasis on different network dimensions, which may make people missing out on other dimensions.

The rate of reciprocation, that is the links where both nodes named each other as a fraction of all links where at least one mentioned the other, is for general relations with 30.2 percent similar to the reciprocation rate of 36.7 percent reported by Leider et al. (2009) who elicited only friendship networks. The rate of reciprocated ties decreases for the more specific network contents. This is not surprising because there exists a trade-off between capturing multiple network dimensions and reciprocated ties. Different people likely put different emphasis on different dimensions of relations, lowering the rate of

Table B.1: Reciprocation rates

\begin{tabular}{lc}
\hline \hline & Reciprocation $^{\mathrm{a}}$ \\
\hline General relation & 0.302 \\
Friendship relation & 0.115 \\
Support relation & 0.021 \\
Neighbor relation & 0.145 \\
Social public activities & 0.171 \\
Economic relation & 0.088 \\
\hline
\end{tabular}

Note: ${ }^{a}$ all two-sided links as a fraction of all one-sided links, intra-household relations between household heads are ignored.

reciprocated ties when asked to describe their specific relations. As the reciprocation rates in Table B.1 show especially support relations and economic relations have very low reciprocation rates. This can be explained by the asymmetric nature of such relations. In support relations, givers and receivers of support are unlikely to put the same emphasis on this type of social relation. That this is indeed the case is supported by the following observation. Considering all one- and two-sided support relations, we find that nodes who posses cattle, i.e. potential support givers, mention their relation significantly less often than nodes without cattle, i.e., potential support receivers $(50.5$ percent versus 66.2 percent; $p=0.005$ two-sided $\chi^{2}$-square test). A similar result holds when comparing nodes with and without land (45.1 percent versus 65.8 percent; $p<0.001$ two-sided $\chi^{2}$-square test). A similar argument holds for economic relations. 


\section{B.2 Closed and Open Triples and Clustering}

The clustering coefficient reported in Table 2 in the main text is defined as the ratio of the number of open and closed triples in the network. For completeness we report them here.

Table B.2: Closed and open triples and clustering in the different networks

\begin{tabular}{lccc}
\hline \hline & $\begin{array}{c}\text { Number of } \\
\text { closed triples }\end{array}$ & $\begin{array}{c}\text { Number of } \\
\text { open triples }\end{array}$ & $\begin{array}{c}\text { Clustering } \\
\text { coefficient }\end{array}$ \\
\cline { 2 - 4 } General relation & 22862 & 67077 & 0.254 \\
Friendship relation & 3982 & 26059 & 0.133 \\
Support relation & 58 & 1396 & 0.040 \\
Social public activities & 260 & 2817 & 0.085 \\
Economic relation & 176 & 4094 & 0.041 \\
Neighbor relation & 157 & 2741 & 0.054 \\
\hline
\end{tabular}

Note: OR-networks, intra-household relations (not) counted as valid links in general, friendship, extended family, and support relations (neighbor, social public activities, and economic relations).

\section{B.3 Additional Regressions}

Table B.3 shows the regression results of an alternative to Model 3 in Table 5 and the specifications shown in Table [in the main text. Here the inverse of the squared number of links between dictator and recipient is used to measure distance in the networks instead of a dummy variable that takes value zero when the dictator and the recipient are not directly connected. A comparison of the regression results shown here with those in Tables $[5$ and $[6$ indicates that the results are qualitatively the same. 
Table B.3: Determinants of directed generosity in the general and specific networks (inverse squared distance)

\begin{tabular}{|c|c|c|c|c|c|c|c|c|c|c|}
\hline \multirow[b]{2}{*}{ Male $\rightarrow$ Female } & \multicolumn{10}{|c|}{ Dependent variable: Coins given to village recipient } \\
\hline & $3.058^{* * *}$ & $(1.128)$ & $2.443^{* *}$ & $(1.181)$ & $2.382^{* * *}$ & $(0.791)$ & $2.489^{* * *}$ & $(0.870)$ & $1.507^{*}$ & $(0.864)$ \\
\hline Female $\rightarrow$ Female & $1.413^{*}$ & $(0.823)$ & 0.761 & $(0.835)$ & $1.368^{* *}$ & $(0.658)$ & $1.329^{* *}$ & $(0.618)$ & $1.080^{*}$ & $(0.640)$ \\
\hline$A g e \_D$ & 0.042 & $(0.043)$ & 0.058 & $(0.042)$ & 0.057 & $(0.045)$ & 0.041 & $(0.045)$ & 0.050 & $(0.044)$ \\
\hline Education_D & 0.041 & $(0.140)$ & 0.037 & $(0.119)$ & 0.049 & $(0.145)$ & -0.028 & $(0.152)$ & -0.041 & $(0.133)$ \\
\hline Education_s & -0.050 & $(0.087)$ & -0.021 & $(0.081)$ & -0.015 & $(0.078)$ & -0.001 & $(0.077)$ & 0.006 & $(0.076)$ \\
\hline Residence_D & -0.032 & $(0.027)$ & -0.043 & $(0.031)$ & -0.037 & $(0.029)$ & -0.036 & $(0.031)$ & -0.035 & $(0.029)$ \\
\hline Residence_s & -0.006 & $(0.023)$ & -0.012 & $(0.023)$ & -0.008 & $(0.022)$ & -0.005 & $(0.020)$ & -0.006 & $(0.023)$ \\
\hline NoCattle $\rightarrow$ Cattle & -0.555 & $(0.769)$ & -0.916 & $(0.730)$ & -0.882 & $(0.713)$ & -1.222 & $(0.741)$ & -0.660 & $(0.762)$ \\
\hline NoCattle $\rightarrow$ NoCattle & -0.337 & $(0.819)$ & -0.424 & $(0.859)$ & -0.535 & $(0.928)$ & -0.733 & $(0.972)$ & -0.308 & $(0.865)$ \\
\hline Land $\rightarrow$ NoLand & -0.213 & $(0.916)$ & -0.091 & $(0.871)$ & -0.388 & $(0.878)$ & -0.422 & $(0.907)$ & -0.442 & $(0.929)$ \\
\hline NoLand $\rightarrow$ Land & -0.657 & $(1.038)$ & -0.153 & $(0.946)$ & -0.134 & $(1.068)$ & -0.716 & $(1.007)$ & -0.663 & $(0.993)$ \\
\hline NoLand $\rightarrow$ NoLand & -0.823 & $(1.005)$ & -0.476 & $(0.898)$ & -0.001 & $(1.126)$ & -0.668 & $(1.033)$ & -0.885 & $(0.984)$ \\
\hline $1 /$ Distance $^{2}$ & $1.246^{*}$ & $(0.693)$ & $1.487^{*}$ & $(0.882)$ & 0.795 & $(1.144)$ & -0.785 & $(1.306)$ & -0.620 & $(1.142)$ \\
\hline Closure_D & -0.003 & $(0.003)$ & $-0.011^{*}$ & $(0.006)$ & $0.294^{*}$ & $(0.166)$ & -0.019 & $(0.034)$ & $-0.151^{*}$ & $(0.082)$ \\
\hline Centrality_D & 1.435 & $(1.213)$ & $0.791^{* *}$ & $(0.307)$ & -0.189 & $(0.128)$ & 0.291 & $(0.403)$ & $0.510^{* * *}$ & $(0.190)$ \\
\hline $\mathrm{R}^{2}$ & \multicolumn{2}{|c|}{0.4497} & \multicolumn{2}{|c|}{0.4602} & \multicolumn{2}{|c|}{0.4469} & \multicolumn{2}{|c|}{0.4407} & \multicolumn{2}{|c|}{0.4909} \\
\hline F-statistics & \multicolumn{2}{|c|}{8.62} & \multicolumn{2}{|c|}{11.01} & \multicolumn{2}{|c|}{9.37} & \multicolumn{2}{|c|}{8.24} & \multicolumn{2}{|c|}{13.30} \\
\hline Prob $>F$ & \multicolumn{2}{|c|}{0.0000} & \multicolumn{2}{|c|}{0.0000} & \multicolumn{2}{|c|}{0.0000} & \multicolumn{2}{|c|}{0.0000} & \multicolumn{2}{|c|}{0.0000} \\
\hline No. of obs. & \multicolumn{2}{|c|}{273} & 27 & & 273 & & 27 & & 27 & \\
\hline
\end{tabular}

Note: ${ }^{* * *},{ }^{* *},{ }^{*}$ indicate two-sided significance levels at 1,5 , and 10 percent, respectively; ${ }^{\text {a }}$... decision fixed effects are not significant (n.s.); robust standard errors (in parentheses) are obtained by means of two-way clustering at the level of dictators (57 clusters) and recipients (91 clusters). 


\section{B.4 Visualization of Different Network Dimensions}

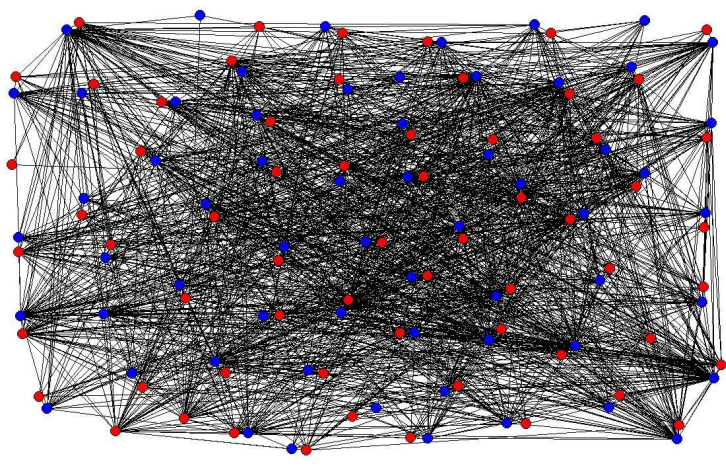

(a) Friendship network

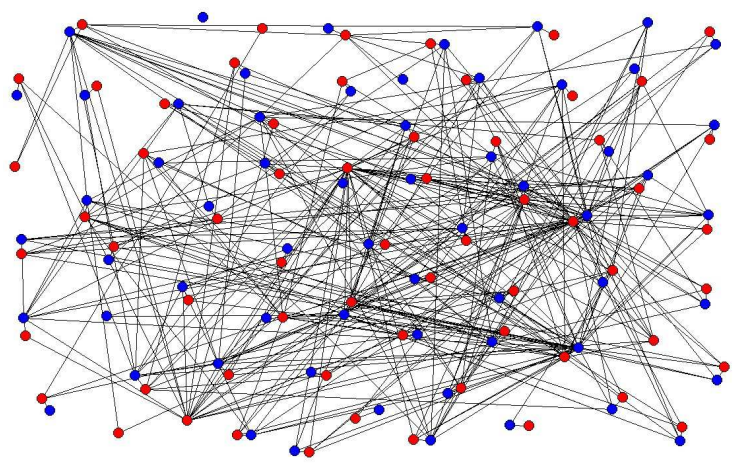

(c) Support network

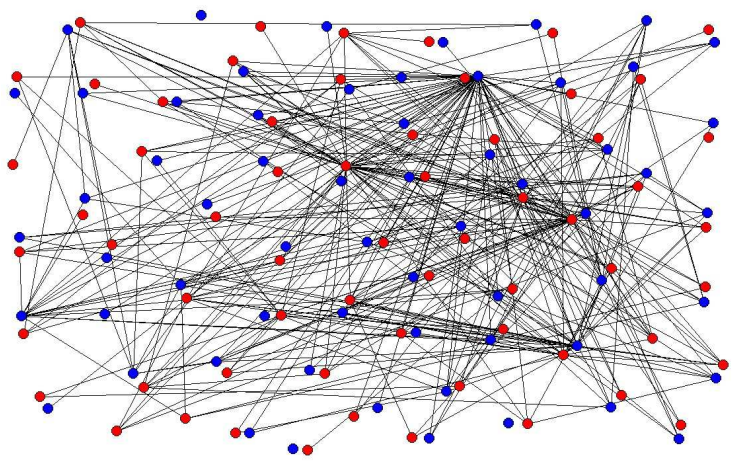

(b) Economic network

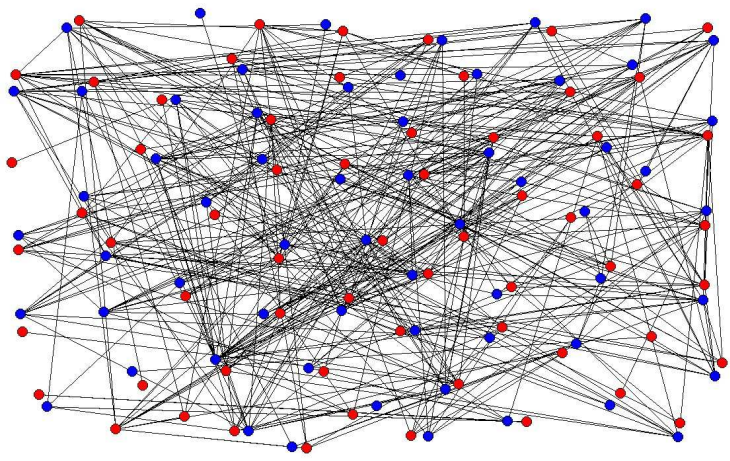

(d) Neighbors network

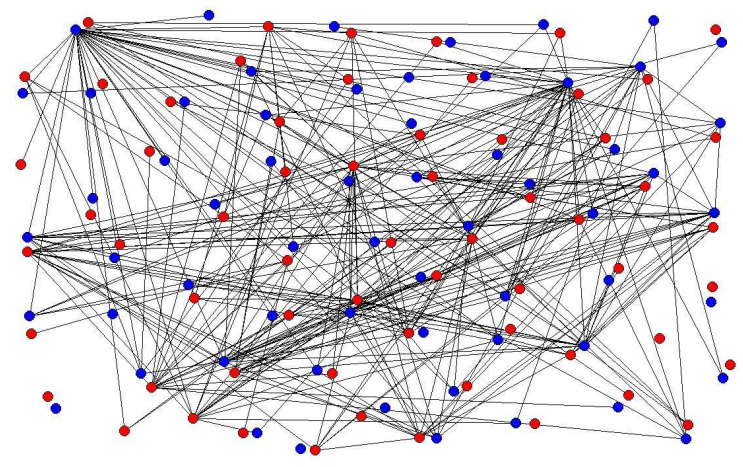

(e) Network through social public activities

Note: Household heads of the same household are placed next to each other.

Figure B.1: Different specific networks 